\title{
Lowering Saudi Arabia's fuel consumption and energy system costs without increasing end consumer prices
}

\author{
Walid Matar, Frederic Murphy, Axel Pierru and Bertrand Rioux
}

\section{Summary}

Saudi Arabia aims to reduce the growth of its energy demand. This paper outlines an approach that could help the country to reduce substantively its current fuel consumption and could result in a net economic gain without increasing current end consumer prices and while maintaining positive utility sector net cash flows. Using a new multi-sector equilibrium model developed by KAPSARC (the KAPSARC Energy Model or KEM), we estimate the magnitudes of the potential economic gains that different policies would generate.

Our long term static version of the model reveals that an annual economic gain exceeding 23 billion USD in 2011 , or almost $5 \%$ of that year's GDP, could have been achieved while the water and power sectors continue to live within their cash flows. Our approach - which introduces investment credits for solar and nuclear and allows more natural gas consumption in the power sector-achieves almost all the benefit of raising inter-sector transfer prices for fuels to world market equivalences, but only moderately increases current transfer prices. Importantly, this gain does not require an increase in consumer prices of electricity or water.

The main conclusions of this work are the following:

- Our modeling shows it is possible to solve the apparent contradiction of inducing greater efficiencies and lower energy consumption, while preserving current consumer prices.
- All scenarios lead to substantive reductions in fuel consumption and attractive net economic gains when compared to the baseline scenario. The Price-deregulation scenario, which prices fuels at the marginal value, yields the highest net gain, but those gains are broadly matched by the gains achieved with the Investment-credit option. Furthermore, the latter option maintains the profitability of the utilities.

- The net economic gain is impacted by the assumed value of oil saved, which also affects the optimal equipment mix, but that gain is always positive irrespective of the chosen value of oil saved.

- In all scenarios, the economic gain for the nation as a whole, as well as for the government, is substantial. The petrochemical and utilities sectors suffer reduced net revenues relative to the baseline scenario, but those losses are more moderate in the Investment-credit scenarios and would be ameliorated in practice by honoring the terms of existing contracts.

Our approach is consistent with decentralized decision making, allowing price incentives to guide efficient investment decisions, and avoids the supervisory burden that top-down planning would impose. Furthermore, it maximizes the societal gain that can be achieved without burdening end consumers with higher prices. 


\section{About KAPSARC}

The King Abdullah Petroleum Studies and Research Center (KAPSARC) is an independent, non-profit research institution dedicated to researching energy economics, policy, technology, and the environment across all types of energy. KAPSARC's mandate is to advance the understanding of energy challenges and opportunities facing the world today and tomorrow, through unbiased, independent, and high-caliber research for the benefit of society. KAPSARC is located in Riyadh, Saudi Arabia.

\section{Legal notice}

(C) Copyright 2014 King Abdullah Petroleum Studies and Research Center (KAPSARC). No portion of this document may be reproduced or utilized without the proper attribution to KAPSARC. 


\section{Policy insights}

Our work illustrates the potential of some possible policy options to reduce the growth of internal primary energy demand and provides insights for reducing total energy costs in the Saudi economy, while still satisfying current social goals. These insights have the potential to be useful in formulating future Saudi energy policy.

\section{Balancing economic and social goals}

The generally held notion is that the best way to reduce the inefficiencies associated with currently low domestic energy prices is to use price incentives, by moving to world market prices throughout the economy. However, this would force higher prices on consumers, and that would undermine the social goal of making energy affordable to society. As a start to improving the efficiency of energy use in Saudi Arabia, we examine the potential for improvements in energy-intensive sectors while maintaining consumer prices at current levels.

KAPSARC developed a multi-sector economic equilibrium model, the KAPSARC Energy Model (KEM). By implementing it in this particular study for Saudi Arabia, we are able to show how the country has the potential to reduce current energy consumption and attain a substantive net economic gain without altering consumer prices, while keeping targeted sectors within reasonable budgets. Moreover, the policy approaches examined in this paper lead to more efficient infrastructure investments that lessen the budgetary effects of administered prices on Saudi Arabia. That is, the economy and the national budget can become more efficient without forcing higher costs on Saudi citizens.

\section{Preserving the efficiency of decision making}

Economists take the position that decentralized decision making in the form of full deregulation of prices leads to the most economically efficient allocation of resources and investments, and that competitive markets attain the greatest economic gains for society as a whole. In principle, these gains can also be achieved by extending government control to all investment and production decisions, thus micromanaging the economy. Extending this level of control would, however, require prescriptive regulation of participants and their investment plans and impose a heavy regulatory overhead that could lessen the growth potential of the Saudi economy. A "market-based" solution would typically be more efficient to manage than a system with centralized decision making.

In this paper, we show that transfer prices of fuels can be administered to align each sector's interest with the interests of the economy at large. That is, the organizations in the sectors examined here make decisions that both meet their interests and increase the overall economic gain without top-down planning - given the right incentives.

\section{Long term static model calibrated on 2011}

The results we present in this paper are based on calibrating our model with 2011 data. We illustrate the potential outcomes of alternative regulatory and investment decisions by comparing current policies with alternatives, allowing additional investment with the benefit of hindsight. In other words, we consider what would have happened if the sectors had been able to revisit 2011 with the incentives provided by current and alternative policies, and add new infrastructure to the pre-existing facilities. As previously stated, consumers see no increase in their tariffs in any of the scenarios examined. Preliminary results of the model and input from experts were discussed at KAPSARC's Energy Systems Modeling Workshop in Washington DC and at the INFORMS annual meeting in Minneapolis, both in late 2013. Based on these discussions and others in Saudi Arabia, we revised the inputs for the costs of solar 
and nuclear and the efficiency of new combinedcycled units in the power sub-model (see Appendix 1, Tables A1 and A2). Furthermore, we are continually expanding the model to cover energy intensive sectors of the Saudi economy, and have recently added the cement sector.

In valuing the energy saved, we assumed that any oil and gas no longer required domestically is valued at world prices. Saudi Arabia may not be able to export the oil saved today, however, as the country currently maintains a cushion of spare capacity. Nonetheless, this cushion is expected to shrink in the medium to long term, given current rates of demand growth both domestically and globally, while the infrastructure capacity suggested by the model will last for several decades - perhaps after the cushion is gone. Because the timing of exports is uncertain, we analyze the sensitivity of the estimated economic gains to the value attributed to the oil saved in the long-term static version of the model used here. These results are presented in Section 6 below.

\section{Our conclusions are:}

- Maximizing economic gain without altering consumer prices, by deregulating the inter-sector fuel prices, could reduce domestic oil consumption by 860,000 barrels of oil per day and provide a net economic gain of 23.7 billion USD per year to Saudi Arabia compared to the status quo. Achieving this outcome would involve pricing crude oil at its export price for transactions among sectors. Either the utilities would absorb the resulting costs of selling to consumers at a loss or these losses could be covered by output subsidies or financial transfers.

- Letting natural gas (methane) flow to sectors where it has the greatest direct value would lead to lower gas consumption in the water and petrochemical sectors and increased consumption in electricity generation. There might be some offsetting losses due to indirect and induced-employment effects in the petrochemical and other sectors. However, these and other equilibrium effects, including the impact of reinvesting the savings in other employment generating activities, are not quantified in the model nor are they within the scope of this research.

- By introducing investment credits in the power sector, smaller fuel-price increases can realize almost the full economic gain and reduction in domestic oil consumption that could be achieved by using internationally comparable fuel prices. In other words, this investment credit policy gives an economic gain that is almost equivalent to that of deregulating inter-sector fuel prices. For any given combination of transfer prices for oil and gas, KEM optimizes the credits to maximize the economic gain in the energy system. We provide illustrative combinations of fuel prices and investment credits that could secure more than 23 billion USD of annual economic gains in 2011. The utility sector would still break even, but the economic incentives align decisions in the power sector with the goals of the economy as a whole, in contrast to the baseline scenario of providing inexpensive fuel to the utilities, which leaves them with little incentive to upgrade their power plants to more efficient technologies.

- Providing investment credits or setting fuel prices at the levels that maximize economic gain would lead to substantial solar and nuclear penetration and the elimination of crude oil consumption in electricity generation.

\section{Results overview}

Reducing total energy demand without altering consumer prices or end-use demand can be achieved only by reducing intermediate energy demandfuels for energy transformation in the power sector 
and inputs to energy intensive sectors. In this initial analysis, we particularly focus on the electricity and water sectors and the impact of fossil fuel prices to encourage optimal usage. This arises through installing more efficient capital equipment (combined cycle gas turbines and reverse osmosis desalination) or technologies that do not burn fossil fuels (solar and nuclear in particular).

\section{Scenarios examined}

One of the features of the present arrangements in the Saudi energy economy is that, at the current domestic price of natural gas, demand exceeds the economically viable domestic supply. Natural gas is therefore allocated by the Ministry of Petroleum and Mineral Resources and each sector receives a quota. This arrangement is reflected in the Current-policy baseline. We contrast this with three other alternatives, described more fully in Section 4:

The Constrained-price-adjustment scenario allows a partial adjustment of fuel prices and eliminates the rules for the sectoral allocation of the fixed supply of natural gas. We also impose a constraint that the power and water sectors live within their cash flows. These sectors still purchase fuels at administered prices to balance their budgets.

The difference between the policy options introduced here and the Current-policy baseline is that the administered prices for fuels are determined by KEM, rather than being specified a priori, and natural gas is used where it generates the highest direct economic returns, instead of meeting current sectoral allocations.

The Investment-credit scenarios explore a spectrum of administered fuel prices and power-sector investment-credits. For each combination of administered prices, KEM finds the investment credits for solar and nuclear that maximize direct economic benefits, while the water and power sectors live within their cash flows. We find the optimal mix of credits for solar and nuclear given administered fuel prices. In arriving at the scenarios presented here, we experimented with a range of alternatives, including one where we optimized fuel prices and applied a single investment credit equally to a broad range of fuel-efficient plants. We settled on multiple credits because differentiating the credits by technology improves economic efficiency and a wide range of administered prices produce economic benefits close to the best achieved among the scenarios we examine.

The Price-deregulation scenario measures the impact of pricing fuels at their marginal values without considering the effect on the profitability of the power and water sectors. Marginal value refers here to the economic gain that would result from having an additional unit of fuel available to the Saudi energy system. The marginal values of crude oil and oil products consumed domestically are the export prices. Pricing natural gas at its marginal value allows its 2011 fixed domestic supply to meet domestic demand without imposing sectoral allocations. As a result of much higher fuel prices, the utilities might operate at a loss, but their losses could be covered by a payment from the government to avoid having to change consumer prices to maintain profitability. This scenario sets the upper limit for economic gain from changing transfer prices and eliminating allocation rules.

In a nutshell, none of the options introduced here change the consumer prices. The Constrained-priceadjustment and Investment-credit scenarios constrain expenditures to fit within the revenues of the utilities and preserve price administration but at a higher level, while the Price-deregulation scenario maintains neither of these, see Table 2.1. 


\begin{tabular}{|l|c|c|c|c|}
\hline Policy Scenario & $\begin{array}{c}\text { Fuel Prices } \\
\text { Regulated }\end{array}$ & $\begin{array}{c}\text { Utilities } \\
\text { Financial Losses }\end{array}$ & $\begin{array}{c}\text { Investment } \\
\text { Credit }\end{array}$ & $\begin{array}{c}\text { Change in } \\
\text { Consumer Prices }\end{array}$ \\
\hline Current-policy & Yes & No & No & No \\
\hline Constrained-price-adjustment & Yes+ & No & No & No \\
\hline Investment-credit & Yes+ & No & Yes & No \\
\hline Price-deregulation & No & Yes & No & No \\
\hline
\end{tabular}

Table 2.1: Comparison of the assumptions in the various policy options. The plus sign indicates that the prices are regulated, but at a higher level than the current baseline.

\section{Scope of the analysis}

Any model is, by definition, a simplified representation of reality. KEM relies upon reasonable estimates of input parameters and rational economic decision making. Investment and operating decisions are made based on the prices seen by each sector. Our measure of the effect of policies is the net direct economic gain relative to the Current-policy baseline, determined as the incremental export revenues minus incremental expenditures. These expenditures include non-fuel operating costs and capacity costs (on a levelized annual basis). We perform the cost side of the standard economic-surplus calculation and do not include demand effects because the policies have fixed end-use prices, which results in fixed end-use demand. The model does not consider economic effects such as the employment generated by the petrochemical sector or a solar supply chain versus the employment effects of alternative strategies for investing in the Saudi economy. KAPSARC is undertaking additional studies to explore this impact in due course.

In Table 2.2, we present results from running KEM simulating the year 2011, but allowing a "do over". In other words, all our results derive from long-term single-period equilibria - the capacity already existing in 2011 is available and all capacity "built"

\begin{tabular}{|l|c|c|c|c|c|}
\hline & Current-policy & $\begin{array}{c}\text { Constrained- } \\
\text { price-adjustment }\end{array}$ & $\begin{array}{c}\text { Investment- } \\
\text { credit 1 }\end{array}$ & $\begin{array}{c}\text { Investment- } \\
\text { credit 2 }\end{array}$ & $\begin{array}{c}\text { Price- } \\
\text { deregulation }\end{array}$ \\
\hline $\begin{array}{l}\text { Price of methane - } \\
\text { USD/mmBtu }\end{array}$ & 0.75 & 2.99 & 1.5 & 1.75 & 7.59 \\
\hline $\begin{array}{l}\text { Price of crude oil - } \\
\text { USD/barrel }\end{array}$ & 4.24 & 15.63 & 30 & 45 & 107.80 \\
\hline $\begin{array}{l}\text { Liquid fuels saved - } \\
\text { Barrel millions }\end{array}$ & - & 186 & 315 & 309 & 315 \\
\hline $\begin{array}{l}\text { Incremental export reve- } \\
\text { nues - USD billions }\end{array}$ & - & 17.1 & 29.2 & 28.4 & 30.0 \\
\hline Incremental total cost & - & 1.1 & 5.9 & 5.0 & 6.3 \\
\hline $\begin{array}{l}\text { Net economic gain - } \\
\text { USD billions }\end{array}$ & - & 16.0 & 23.3 & 23.4 & 23.7 \\
\hline
\end{tabular}

Table 2.2: Domestic prices and economic gain for 2011. Source for current-policy prices: Council of Ministers Resolution No. 55. 
by the model is added to this existing capacity. Any shift in the equipment mix implies that new plants can profitably displace production from the already existing plants. This allows alternative pricing and allocation rules to drive capacity investment and fuel consumption outcomes. The latest year for which we could calibrate the model to actual data is 2011.

Although electricity and water consumption are fixed at 2011 levels, energy consumed varies among the scenarios because of different efficiencies and fuel requirements of the chosen capital stock. The incremental export revenues resulting from the policy changes are measured at oil and petrochemical prices realized in 2011. Two specific combinations of administered prices have been selected to illustrate the Investment-credit scenario. For each of these combinations, optimal levels of investment credits for solar and nuclear are determined by the model.

\section{Investment credits versus fuel price deregulation}

Raising fuel prices without making other policy changes is a simple, but blunt, tool. Constrained price adjustments may be expected to deliver a proportion of the economic efficiency that price deregulation offers. Indeed, this is the case. The Constrained-price-adjustment scenario achieves two thirds of the economic gain that results from the Price-deregulation scenario. In the former, intersectoral fuel prices are administered at higher levels than in the Current-policy baseline (but lower than international equivalent prices) and this leads to more efficient investment and fuel consumption patterns, even while keeping end-consumer prices the same. The net result, therefore, is lower fuel consumption.

On the other hand, by adding investment credits, it is possible to ensure economic tradeoffs among fuels and capacity types that are close to the economically efficient tradeoffs observed in the Price-deregulation scenario. As a consequence, the net economic gain with investment credits is close to what can be achieved by the Price-deregulation scenario. In both the Investment-credit and Price-deregulation scenarios, substantial levels of solar and nuclear capacity are built.

To understand how investment credits improve economic efficiency, note that the power sector is assumed to minimize its total cost subject to the constraint of meeting the domestic demand for electricity. Therefore, if all its costs are multiplied by the same factor then the same decisions are optimal before and after scaling. For example, if fuel prices are reduced to one half of the marginal value and a general credit is provided that covers half of all other costs then the same investment and operating decisions would still be made. In our Investment-credit scenarios, only selected investment costs - and no other costs-receive a credit, leading to a different equilibrium than in the Price-deregulation scenario but with very similar economic gains.

\section{Valuing the oil saved}

As a major oil exporting country with spare production capacity, Saudi Arabia may not value a barrel of oil saved from domestic consumption today at the international market price because it may not be possible to sell the incremental barrel saved without affecting the market price of the rest of its sales. Opinions vary as to the correct value to apply. We study the sensitivity of the equipment choices to the value attributed to the oil saved and provide more detail on this sensitivity analysis in Section 6.

\section{The Saudi energy economy}

Classic prescriptions for optimizing the allocation of energy resources in an economy involve price deregulation and market liberalization. However, circumstances do not always support such an 
approach. For example, the structure of the industry may not allow for sufficient participants to create sustainable competition or the energy industry may comprise too large a share of the economy. To understand the context for exploring solutions that fall short of full deregulation, it is worth exploring the characteristics of the Saudi energy economy.

\section{Energy's role in the Saudi economy}

The size of the Saudi energy sector is large relative to the domestic economy. In 2011, the sum of the value added by upstream oil and gas production, oil refining, petrochemical production, power generation, cement production, and water production amounted to around 53\% of the Saudi GDP (CDSI 2014 and GPCA 2012).

Primary domestic fuel consumption is still almost exclusively composed of crude oil and natural gas. Thus, the Saudi energy sector is less complex than those of other larger countries. The Saudi government has, however, announced targets for the development of solar and nuclear power generation capacity.

As Figure 3.1 shows, the domestic demand for primary energy has doubled between 1996 and 2011. It reached 4.46 million barrels of oil equivalent per day in 2012, representing 35\% of the primary energy produced in Saudi Arabia during that year (BP Statistical Review 2013). This sharp increase in energy demand has been driven by demographic changes, expansion of the export-oriented petrochemical industry, and general economic growth. A major component of that growth has been heavy investment in infrastructure, water treatment, and housing.

Because Saudi Arabia has an arid climate, water production is a significant activity and operating desalination facilities entails large amounts of energy consumption. Figure 3.2 shows the increasing demand for desalinated water in Saudi Arabia. This increase reflects both the growth in population and improving living standards. Not only is the water sector a major energy consumer, it is also currently an energy producer, with dual-purpose plants producing both water and power.

\section{Nurturing diversity in the Saudi economy}

In a strategic initiative to diversify the national economy and the country's exports, Saudi Arabia has become a major producer of bulk chemicals. The petrochemical industry's profits are derived partly from the low costs of fuels and feedstocks, primarily natural gas and ethane. The large quantity of natural gas allocated to petrochemicals has led to constraints on the availability of gas to other sectors and the need to develop non-associated gas resources, which have higher production costs than associated gas.

The supporting documents for Saudi Arabia's accession to WTO membership in 2005 explain that natural gas, crude oil, fuel oil, gasoline, diesel, liquefied petroleum gas, natural gas liquids, kerosene, power, and water are part of the list of goods and services subject to domestic price regulation. The document specifies that this policy aims to maintain price stability, secure the needs and welfare of consumers, and preserve important social interests in the country. Furthermore, since these sectors are dominated by large organizations, price regulation is an appropriate approach to control market power.

As a consequence, energy users benefit from low prices administered by government agencies. We use the term "administered" rather than "subsidized" because administered prices that are above production costs do not require government expenditures to keep domestic prices below international prices. Although they are low, crude oil prices exceed domestic production costs and the 


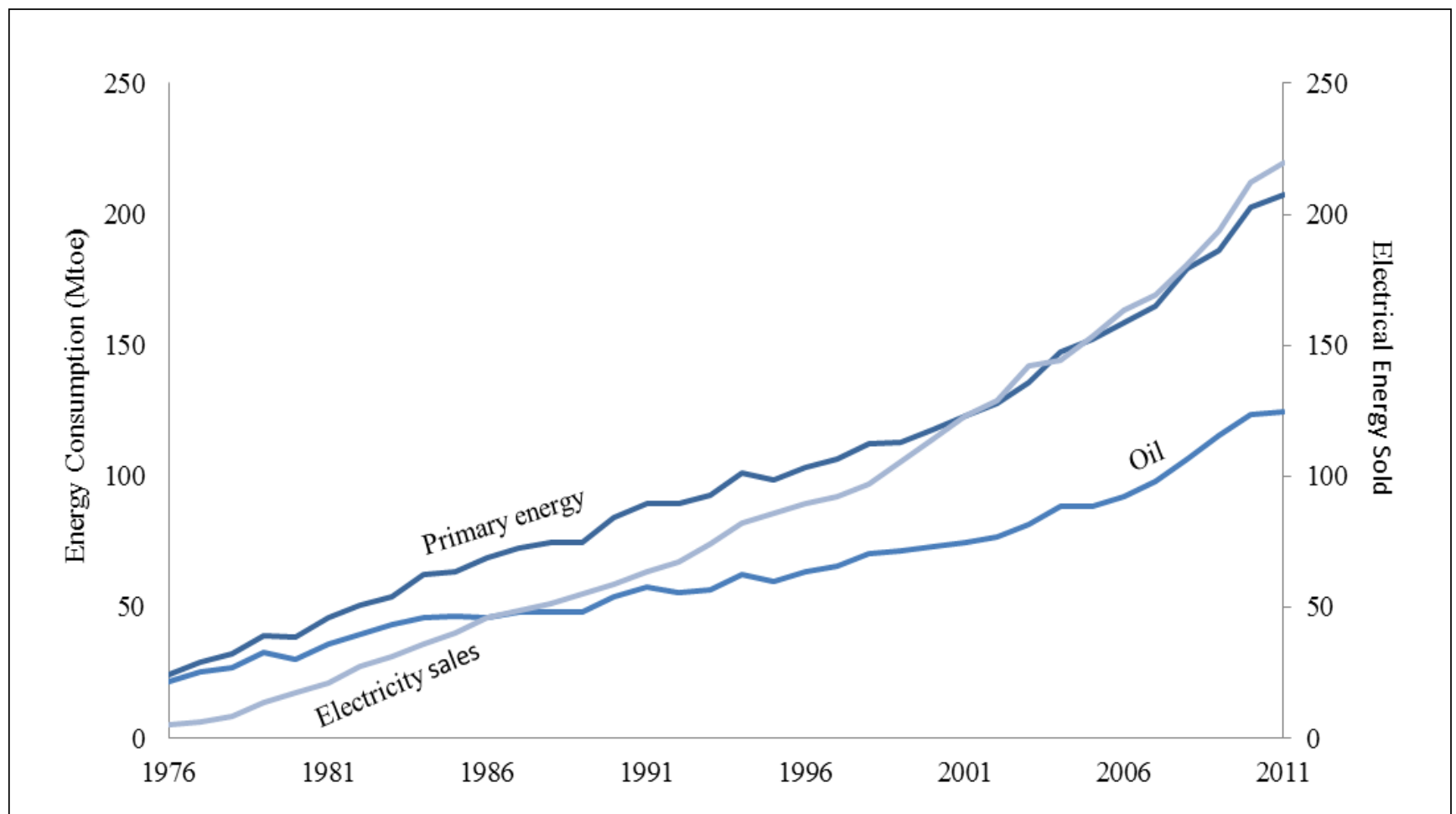

Figure 3.1: Saudi domestic demand for oil, primary energy (oil plus natural gas), and electricity (1976-2011). Source: Electricity sales: Saudi Arabian Monetary Agency (SAMA, 2012), oil and primary energy consumption: BP Statistical Review (2013).

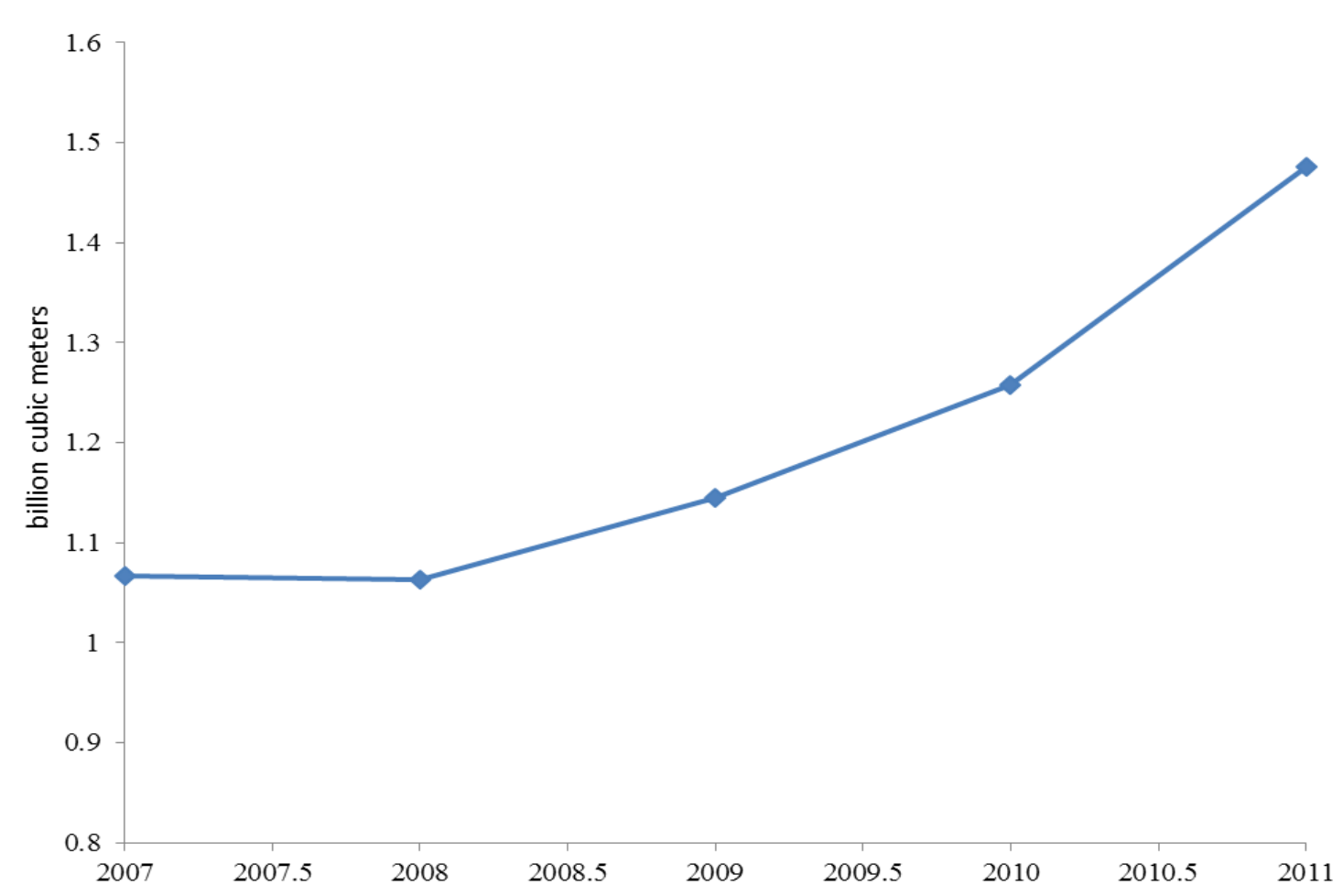

Figure 3.2: Demand for desalinated water. Source: Ministry of Water and Electricity (2012). 
natural gas price may still be above the weighted average costs of associated and non-associated production.

The nominal prices of diesel and regular gasoline have been fixed at 0.25 SAR per liter (0.252 USD per gallon based on the fixed exchange rate of 1 $\mathrm{USD}=3.75 \mathrm{SAR})$ and $0.45 \mathrm{SAR}$ per liter $(0.454$ USD per gallon), respectively (Royal Decrees, 2006). The Saudi Electricity Company reports that the overall average electricity tariff paid by consumers was $0.13 \mathrm{SAR} / \mathrm{kWh}$ (3.5 US cents/kWh) in 2010 (SEC 2012).

Inter-sector energy prices are also administered to lessen the losses of utilities and favor the development of certain industrial activities, such as petrochemical production. The residential, commercial, and governmental sectors see electricity prices that are based on the level of consumption. The electricity pricing structure for industrial use has been modified to account for seasonality and peaktime effects. Table 3.1 gives the prices of fuels for

\begin{tabular}{|c|c|c|}
\hline & Product & Price \\
\hline Natural gas & $\begin{array}{l}\text { Methane } \\
\text { Ethane }\end{array}$ & $\begin{array}{l}0.75 \text { USD/mmBtu } \\
0.75 \text { USD/mmBtu }\end{array}$ \\
\hline Crude oil & $\begin{array}{l}\text { Arab light } \\
\text { Arab heavy }\end{array}$ & $\begin{array}{l}\text { 4.24 USD/barrel } \\
2.67 \mathrm{USD} / \text { barrel }\end{array}$ \\
\hline $\begin{array}{l}\text { Petroleum } \\
\text { products }\end{array}$ & $\begin{array}{l}\text { Diesel } \\
\text { HFO 360cst } \\
\text { Propane** } \\
\text { Naphtha }\end{array}$ & $\begin{array}{c}3.60 \text { USD/barrel } \\
2.08 \mathrm{USD} / \text { barrel } \\
650 \mathrm{USD} / \text { metric ton } \\
830 \mathrm{USD} / \text { metric ton }\end{array}$ \\
\hline \multicolumn{3}{|c|}{ *Prevailing CFR naphtha prices in Japan minus $28 \%$} \\
\hline \multicolumn{3}{|c|}{$\begin{array}{l}\text { Table 3.1: Local prices for the domestic power, water and } \\
\text { petrochemical sectors in 2011. Source: National Commercial Bank } \\
\text { (2012), Council of Ministers Resolution No. 55, and ECRA. }\end{array}$} \\
\hline
\end{tabular}

power and water production and feedstocks for the local petrochemical industry in 2011 .

Since domestically produced natural gas is consumed entirely within the country and none is imported, a low administered price combined with constrained supply means the quantities available have to be allocated to the major gas-consuming sectors. Quotas of natural gas are allocated by the Ministry of Petroleum and Mineral Resources, using sectoral demand estimates.

\section{Definition of alternative policy scenarios}

We examine several pricing scenarios for intersector fuel prices, including the existing policy, prices set to marginal values (as a benchmark for economic efficiency), and alternative fuel-pricing and investment-credit mechanisms. As a measure of economic gain for each scenario, potential export revenues and the total cost of meeting domestic enduse demand are computed. The total cost for the entire energy sector is the sum of non-fuel costs incurred in all sub-models. Again, we use the term potential export revenues, noting that the oil might be produced in future years at future prices. Our calculation excludes all inter-sector transfers, as the payments and revenues from payments net out in the total cost/benefit calculation. To quantify the value of the change in potential export revenues, we use the average international market prices of products in 2011. For instance, Arab Light crude is priced at 107.80 USD per barrel. Net economic gains are calculated incrementally from the Current-policy baseline.

A brief description of the model and its calibration is contained in Appendix 1, along with notes on how we implemented the scenarios. We study various scenarios, along with the Current-policy baseline described below. These scenarios are chosen to illustrate the potential for savings. 


\section{Current-policy baseline}

The Current-policy baseline uses the administered prices and fuel allocations currently in place in Saudi Arabia. The administered inter-sector prices are provided in Table 3.1. The model fails to find a market equilibrium in the absence of quotas, since the low administered price for natural gas is not linked to the physical availability of gas. The total quantity of gas demanded by the power, water, petrochemical, and cement sectors exceeds the available supply, and the Ministry has to allocate the available supply. We impose the quotas in Table 4.1 for the power, water, petrochemical, and cement sectors, for a total of 3.2 quadrillion British thermal units (qBtu) in 2011. In the cement sector, the use of heavy crude oil is also restricted to the quantity actually allocated in 2011 .

\section{Price-deregulation scenario}

In this scenario, the inter-sector fuel prices are determined in the model and are set to marginal values that match supply with demand. For crude oil and oil products consumed domestically, the marginal values include the cost of having lower export revenues, which passes world market prices through to the consuming sectors. Since we assume end-user prices do not change, this implies the power and water sectors lose money. The use of gas is endogenously determined in the model with the available gas flowing to where it has the highest value, given the overall supply availability. This scenario maximizes net economic gain and corresponds to the equilibrium with competitive markets, the most economically efficient outcome, given the caps on the prices for electricity and water.

\section{Constrained-price-adjustment scenario}

The Constrained-price-adjustment scenario is an intermediate case. While the Price-deregulation scenario provides a benchmark for economic

\begin{tabular}{|l|c|c|}
\hline & Methane & Ethane \\
\hline Power sector & 0.90 & \\
\hline Water sector & 0.35 & \\
\hline $\begin{array}{l}\text { Petrochemical } \\
\text { sector }\end{array}$ & 0.90 & 0.51 \\
\hline Cement sector & 0.07 & \\
\hline Other industrials & 0.47 & \\
\hline \multicolumn{2}{|l|}{$\begin{array}{l}\text { Table 4.1: Current allocation of natural gas, in qBtu. Source: } \\
\text { KAPSARC estimates based on publicly available information. }\end{array}$} \\
\hline
\end{tabular}

efficiency, it leads to financial losses in the power and water sectors, unless the national treasury pays the difference between the utilities' costs and revenues from consumers. The Constrained-priceadjustment scenario adopts administered prices that achieve a certain degree of efficiency by allowing prices to change and eliminating allocation rules. It limits the costs incurred in the utilities sectors by imposing a budget constraint that restricts the total costs incurred by the power and water sectors to stay within their total operating revenues, set at 10 billion USD. This cost is estimated after netting out payments between the water and power sectors. It is an approximation of the budget for facility purchases, plant fuel purchases, and operations and maintenance-its actual value is obscured by accounting for overhead, depreciation, and a certain level of profitability. Appendix 1 contains details of how we find the equilibrium and determine the prices in this scenario.

\section{Investment-credit scenarios}

The Investment-credit scenarios explore a spectrum of administered fuel price and power plant 
investment-credit combinations. We examine credits for investments in solar and nuclear power plants only. For a given combination of administered prices we find the investment credits for solar and nuclear capacity that maximize economic benefits, while the water and power sectors live within their cash flows, as we do in the Constrained-price-adjustment scenario. The power sector acquires capacity at a cost equal to the actual investment cost, reduced by the credit associated with that type of plant.

There is a great deal of latitude in defining an investment-credit policy: what types of capacity get the credit and whether the credit should be the same for all types of capacity. In our initial experiments, we defined the credit to be the same for all energyefficient technologies. We settled on the restricted, differentiated credits for three reasons. First, we learned from our experiments that the economic-gain curve is quite shallow. That is, a wide range of administered prices produce roughly the same economic gains as the best combination. Consequently, Saudi Arabia can choose from among prices with a small reduction in the potential economic gain when meeting goals beyond maximizing economic surplus, as long as the investment credits are optimized for those prices. Second, calculating different investment credits for solar and nuclear, rather than a single credit for all fuel-efficient technologies, increases the economic gain. Third, differentiated credits allow for shaping the mix of solar and nuclear plant additions, while achieving economic gains that are similar to those in the Price-deregulation scenario. Thus, other policy considerations, such as the development of solar and nuclear supply chains, can enter into setting incentives for the investment decisions.

Prices of heavy fuel oil and diesel depend on the administered price of crude oil. The administered price of ethane remains equal to that of methane, adjusted for energy content. All oil-based feedstock prices are fixed to the values used in the Currentpolicy scenario. The simulations are run without enforcing natural gas quotas by sector or region: the gas flows where it is the most valuable and the resulting consumption within sectors gives the optimal quotas.

In all scenarios, as a simplified representation of environmental rules, the use of heavy fuel oil in the power and water sectors is restricted to the quantities

\section{An example of unintended consequences: Cogen desalination plants}

In Table 4.1, the quota allocated to the water sector includes the fuel consumed by dual-purpose plants which cogenerate electricity. These desalination plants sell electricity to the power company at a price fixed in long-term contracts. As far as we know, this price remains fixed whatever the time of the day. This does not create any incentive to use the water plants for peak shaving, in spite of the ability of multi -stage flash plants to vary their product mix between water and electricity during the day. This fixed price is maintained in all of the scenarios studied, providing an incentive to generate as much electricity as possible when the natural gas price is low, and shutting down the plants in favor of reverse osmosis units in scenarios where the gas price is higher.

It is likely that these existing thermal desalination plants could provide cost effective peak generation capacity on a sunk cost basis but the current prices of natural gas, water, and electric power do not encourage this economically efficient outcome. 
actually consumed in 2011. The use of heavy fuel oil in the cement sector is also restricted to 2011 levels. Moreover, in the refining, petrochemical, and cement sub-models we limit the quantities exported to those observed in 2011.

\section{Detailed results}

In all scenarios, changing fuel input prices to the modeled sectors results in building new capacity and idling the least efficient existing capacity. In the long-run static model version of KEM, capacity costs are the single-year levelized annual costs (excluding the sunk capital costs of existing capacity), and operating costs are presumed to be constant throughout the life of the equipment. This formulation can also be thought of as one that takes a myopic view where current fuel and operating costs are used in determining the capacity that is acquired. In each sub-model, the most economic capacity is built, given the prices the sector sees. Since the capacity available in 2011 is the existing capacity, the large capacity additions that arise in some of the scenarios reflect the scale of the economic benefits that result from the alternative policies. This outcome, that the full cycle costs of new capacity are less than the marginal costs of running existing capacity, suggests that these

\begin{tabular}{|l|l|l|}
\hline \multirow{2}{*}{ Ethane } & Petrochemicals & 24.41 \\
\hline \multirow{3}{*}{ Methane } & Power & 0.82 \\
\cline { 2 - 3 } & Water & 0.80 \\
\cline { 2 - 3 } & Petrochemicals & 1.87 \\
\cline { 2 - 3 } & Cement & 2.44 \\
\hline $\begin{array}{l}\text { Table 5.1: Marginal value of natural gas (USD/mmBtu) in the Eastern } \\
\text { region, Current-policy scenario. }\end{array}$
\end{tabular}

technologies will also be the best choice in meeting future demand growth.

The Current-policy baseline leads to a marginal value of methane that differs according to the sector considered. Because we retain current allocation rules in this scenario, as Table 5.1 shows, the highest marginal values are in the petrochemical and cement sectors. This seems to indicate that the greatest value in the economy would be achieved by allocating any additional quantity of methane to these sectors. This is, however, because in the utility sector the administered price of crude oil, adjusted for energy content, is very close to that of natural gas. Therefore, in both the power and water sectors, burning crude oil is the least-cost substitute for burning the last Btu of gas. The opportunity cost associated with the corresponding gas quotas is therefore very small. Crude oil is generally not a feedstock in the petrochemical sector and we restrict its use in the cement sub-model. Thus, these sectors do not have a low-cost substitute for gas.

Having disparate marginal values for gas in the different sectors, as well as marginal values significantly higher than the supply price, indicates the potential for significant economic gains from different pricing policies that lead to different consumption patterns.

\section{Winners and losers}

All the scenarios examined reveal a net economic gain to the economy at large. But not all sectors share in this gain. Table 5.2 summarizes some of the results obtained in the various scenarios considered. The highest annual economic gain is obtained with the Price-deregulation scenario, which generates 23.7 billion USD relative to the Current-policy baseline.

Table 5.3 shows how the net economic gain is distributed among sectors. This breakdown is 


\begin{tabular}{|c|c|c|c|c|c|c|}
\hline & & $\begin{array}{l}\text { Current- } \\
\text { policy }\end{array}$ & $\begin{array}{c}\text { Constrained- } \\
\text { price-adjustment }\end{array}$ & $\begin{array}{l}\text { Investment- } \\
\text { credit } 1\end{array}$ & $\begin{array}{l}\text { Investment- } \\
\text { credit } 2\end{array}$ & $\begin{array}{c}\text { Price- } \\
\text { deregulation }\end{array}$ \\
\hline $\begin{array}{l}\text { Price of } \\
\text { mmBtu }\end{array}$ & hane - USD/ & 0.75 & 21.33 & 1.5 & 1.75 & 20.92 \\
\hline $\begin{array}{l}\text { Price of } \\
\text { USD } / \mathrm{m}\end{array}$ & $\begin{array}{l}\text { thane - } \\
\text { tu }\end{array}$ & 0.75 & 2.99 & 1.5 & 1.75 & 7.59 \\
\hline $\begin{array}{l}\text { Price of } \\
\text { USD/ba }\end{array}$ & de oil - & 4.24 & 15.63 & 30 & 45 & 107.80 \\
\hline $\begin{array}{l}\text { Energy } \\
\text { qBtu }\end{array}$ & sumed* - & 8.95 & 7.92 & 7.18 & 7.21 & 7.20 \\
\hline $\begin{array}{l}\text { Total cc } \\
\text { billions }\end{array}$ & * - USD & 55.8 & 56.9 & 61.6 & 60.7 & 62.1 \\
\hline & Nuclear & - & - & $88 \%$ & $42 \%$ & - \\
\hline блй & Solar & - & - & $59 \%$ & $28 \%$ & - \\
\hline $\begin{array}{l}\text { Increm } \\
\text { revenue }\end{array}$ & $\begin{array}{l}\text { lexport } \\
\text { USD billions }\end{array}$ & - & 17.1 & 29.2 & 28.4 & 30.0 \\
\hline $\begin{array}{l}\text { Net ecc } \\
\text { USD bi }\end{array}$ & $\begin{array}{l}\text { nic gain - } \\
\text { is }\end{array}$ & - & 16.0 & 23.3 & 23.4 & 23.7 \\
\hline $\begin{array}{l}{ }^{*} \text { Include } \\
{ }^{* *} \text { Cost c } \\
\text { always b }\end{array}$ & $\begin{array}{l}\text { hydrocarbon-b } \\
\text { lations do not ii } \\
\text { laintained to pr }\end{array}$ & $\begin{array}{l}\text { fuels and } \\
\text { de the fixec } \\
\text { reserve n }\end{array}$ & $\begin{array}{l}\text { dstocks } \\
\text { erating costs of pree } \\
\text { ins. }\end{array}$ & sting plants bec & se we assume & these plants will \\
\hline
\end{tabular}

\begin{tabular}{|l|c|c|c|c|}
\hline Sector & $\begin{array}{c}\text { Constrained-price- } \\
\text { adjustment }\end{array}$ & Investment-credit 1 & Investment-credit 2 & Price-deregulation \\
\hline Government & 33.1 & 25.6 & 27.7 & 51.9 \\
\hline Upstream, refining & 3.7 & 3.1 & 3.2 & 5.8 \\
\hline Power & -4.5 & -2.8 & -4.2 & -13.3 \\
\hline Water & -1.1 & -1.1 & -1.1 & -1.6 \\
\hline Petrochemicals & -14.7 & -1.1 & -1.5 & -17.6 \\
\hline Cement & -0.5 & -0.4 & -0.7 & -1.5 \\
\hline
\end{tabular}

Table 5.3: Sectoral economic gains relative to the Current-policy baseline scenario, billion USD. 
calculated using the transfer prices among sectors implemented in each scenario. The gain to the national budget is assumed to be $90 \%$ of the gain realized in the upstream and refining sectors, minus the cost of investment credits. The upstream and refining sectors retain the other $10 \%$ as their economic gain.

Stakeholders are affected differently under the alternative policy scenarios relative to the Currentpolicy baseline.

- In all scenarios, the economic gain for the nation is substantial.

- In the Investment-credit scenarios the economic gains and losses are more moderate for all sectors compared to the Price-deregulation scenario, because of the lower administered prices and investment credits.

- In both the Constrained-price-adjustment and Price-deregulation scenarios the petrochemical and power sectors suffer substantially reduced net revenues because of steep increases in input costs. The losses in these scenarios are a significant portion of revenues for all sectors, except cement.

- In the Current-policy baseline the spending estimate is significantly lower than revenues in the power and water sectors. In the Constrainedprice-adjustment scenario expenditures reach the budget limit of 10 billion USD, leading to the reported loss of profitability. By contrast, in the Investment-credit scenarios profitability is reduced but the investment credits ameliorate the losses and avoid the impact of the budget constraint.

- The distribution of the sectoral gains and losses do not account for existing contracts that fix prices for fuels. These existing contracts mitigate sectoral losses (while reducing the economic gain for the government and upstream and refining sectors by the same amount). At the same time, the new transfer prices would provide the incentives for improving energy efficiency because they apply to the incremental purchases of fuels. To compensate for the sectoral degradation in net revenues not mitigated by current contracts while retaining the total economic gain, it is possible to implement transition mechanisms such as using current prices for some fraction of current fuel consumption or providing a lump-sum subsidy.

\section{Effect of the budget constraint}

It could be argued that the budget constraintensuring that revenues exceed the levelized annual capital and operating costs in the power and water sectors - is an artificial expenditure limit because Saudi Arabia can afford to finance the resulting deficits. If that budget constraint is relaxed in the Constrained-price-adjustment scenario, the net economic gain of 16 billion USD increases progressively as annual costs are allowed to exceed 10 billion USD, as shown in Figure 5.1.

Allowing expenditures to increase to meet higher fuel costs from higher administered prices for fuels can be interpreted as the government providing compensation to the power and water utilities for the increase in domestic fuel prices. The utilities would be free to use this sum in the most efficient way. When the annual spending budget reaches 19.5 billion USD, the budget constraint is no longer binding because no further infrastructure additions are viable in meeting 2011 demand. The fuel prices reach their marginal values, and the equilibrium is the same as that obtained under the Pricederegulation scenario. Because the budget constraint limits the ability to invest, Figure 5.1 illustrates the potential efficiency gains from using higher electricity prices or direct subsidies to expand 


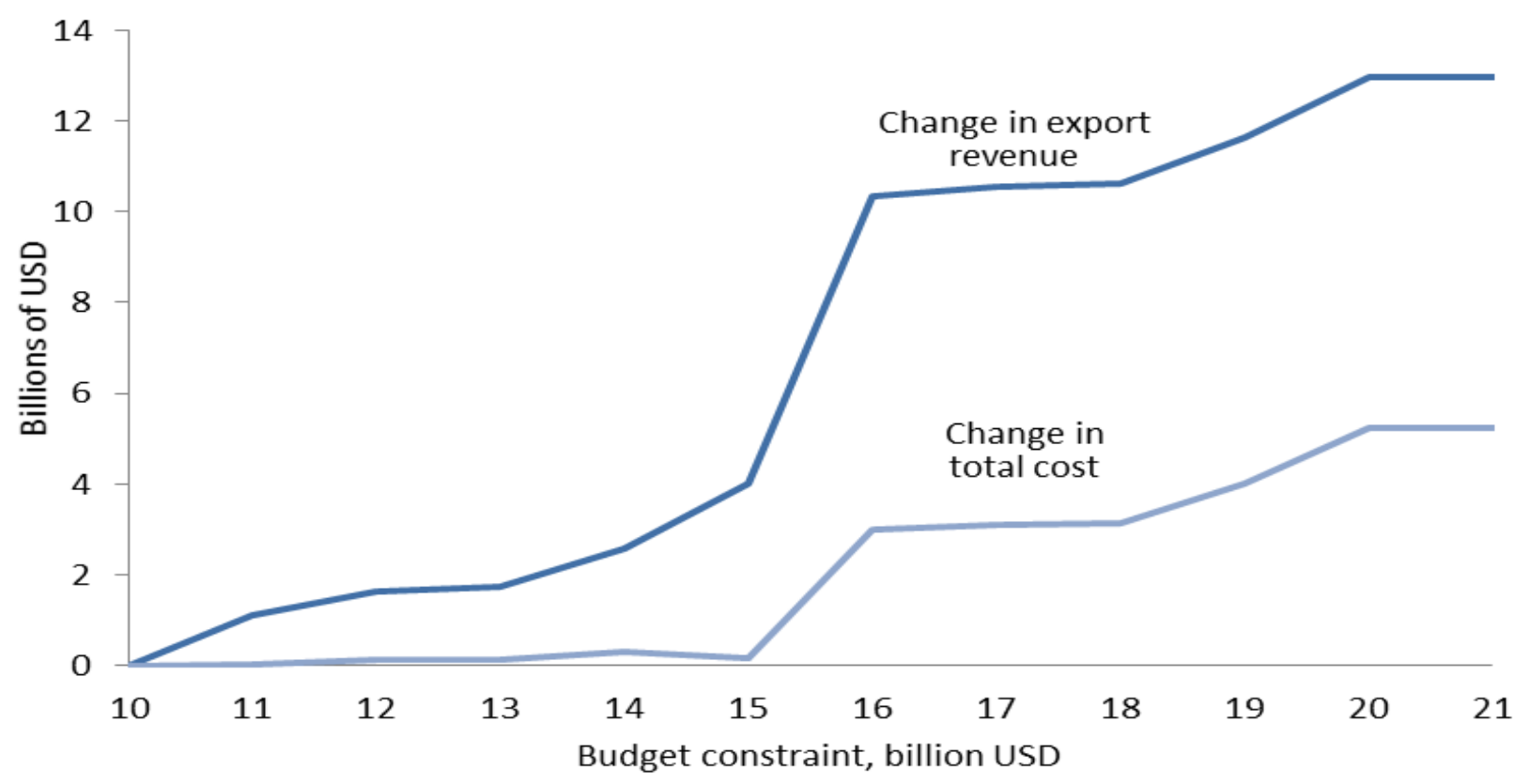

Figure 5.1: Increase in total cost and export revenue as a function of the utility-sector budget constraint, Constrained-price-adjustment scenario.

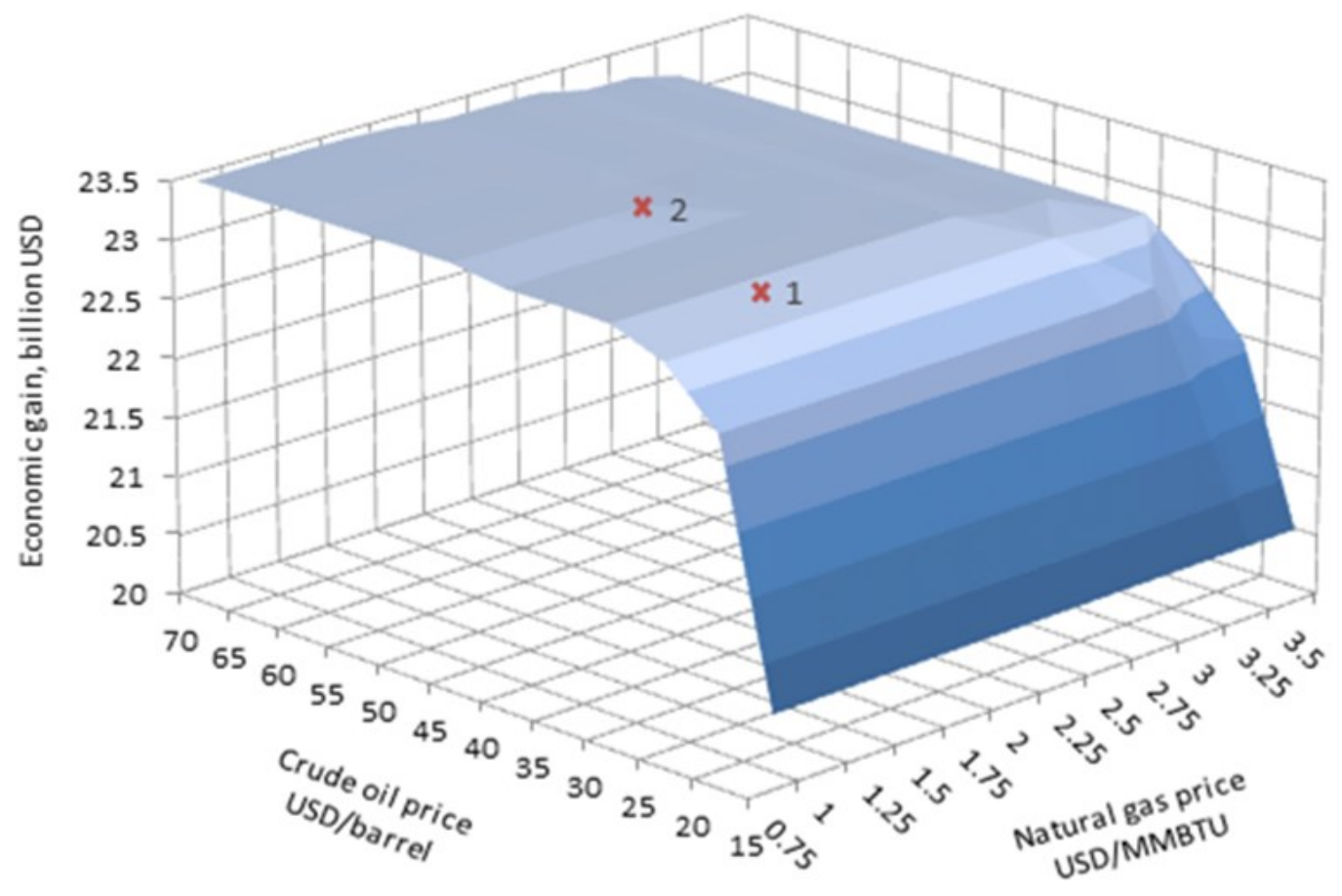

Figure 5.2: Net economic gain surface, Investment-credit scenario. Note: the x's mark Investment-credit scenarios 1 and 2. 
investment in efficient technologies. The higher gains in the Investment-credit scenarios result from the credits reducing investment expenditures, leading to total expenditures below the budget constraint.

\section{Properties of the solution surface}

Figure 5.2 depicts the surface representing the net economic gain over a continuum of administered natural gas and crude oil prices in the Investmentcredit scenarios. The economic gain at each point on the solution surface is the maximum possible economic gain resulting from using the optimal investment credits for solar and nuclear given the oil and gas prices. The optimal levels of the investment credits are a function of the oil and gas costs that are avoided and the costs of the new technologies. In other words, with higher fuel prices, avoiding higher fuel expenditures would require smaller investment credits and lower expenditures on credits to justify the substitution of equipment for fuel.

Each scenario is the solution of a non-linear program subject to equilibrium constraints, an NLPEC. For illustrative purposes, within this scenario we selected two particular policy options in which the oil and gas prices are selected rather than having them determined by the model. Since the solution space is flat, these points are not far from the optimal solution, but this approach has the added advantage of allowing the regulator, still within the region of optimality, to exercise discretion on the level of oil and gas prices. These specific Investment-credit scenarios 1 and 2 are identified in Figure 5.2. Using the model-generated price levels gives broadly equivalent answers. For all combinations of administered prices shown in Figure 5.2 the annual economic gain compared to the Current-policy baseline is more than 20 billion USD.

Two general insights can be extracted from the model results and the shape of the solution surface.
- First, the economic gain increases with the administered price of crude oil. While it is intuitive that less crude oil, diesel, and heavy fuel oil are used when the crude oil price is increased, the surface becomes relatively flat when the administered price of crude oil exceeds 30 USD, as most of the oil consumed in the Current-policy baseline is no longer cost effective in the power and water sectors.

- Second, the higher the administered price of natural gas, the (slightly) lower the economic gain. Because of the budget constraint, a higher administered price of gas reduces the available funds for new investments in more efficient capacity, since the investment credits do not reduce the fixed and variable costs of operating new plants and do not apply to the costs of combined-cycle plants. This shows the limitations of focusing only on parts of an economic system rather than all aspects simultaneously.

Figure 5.3 shows the specific solution surface for Investment-credit scenario 1 . When the investment credits for both solar and nuclear are set to zero in this scenario, the economic gain is 18.1 billion USD because with the administered crude oil price of 30 USD we have a more optimal gas allocation than the Current-policy baseline scenario. Introducing investment credits that balance fuel prices increases the 18.1 billion USD annual economic gain by up to 5.2 billion USD.

Figure 5.4 gives an enlarged view of the portion of the grid where investment credits substantially increase the economic gain. For instance, an investment credit of $25 \%$ of capital costs for solar is sufficient to secure an additional economic gain of 4.3 billion USD (with a total economic gain of 22.4 billion USD) without the construction of nuclear facilities. Note that this figure also highlights that if the investment credit gets too large there can be a 


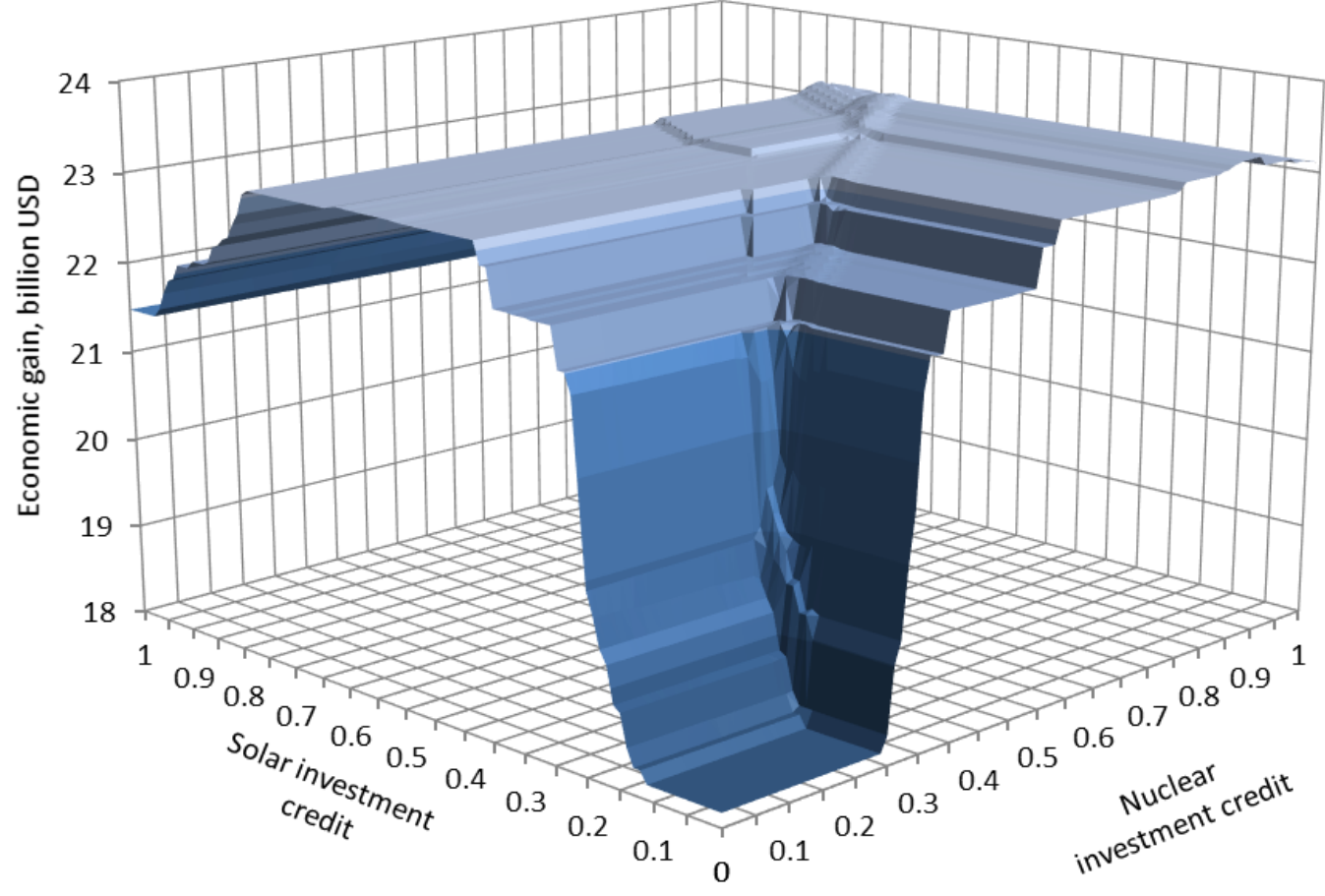

Figure 5.3: Grid of the investment credits, Investment-credit scenario 1.

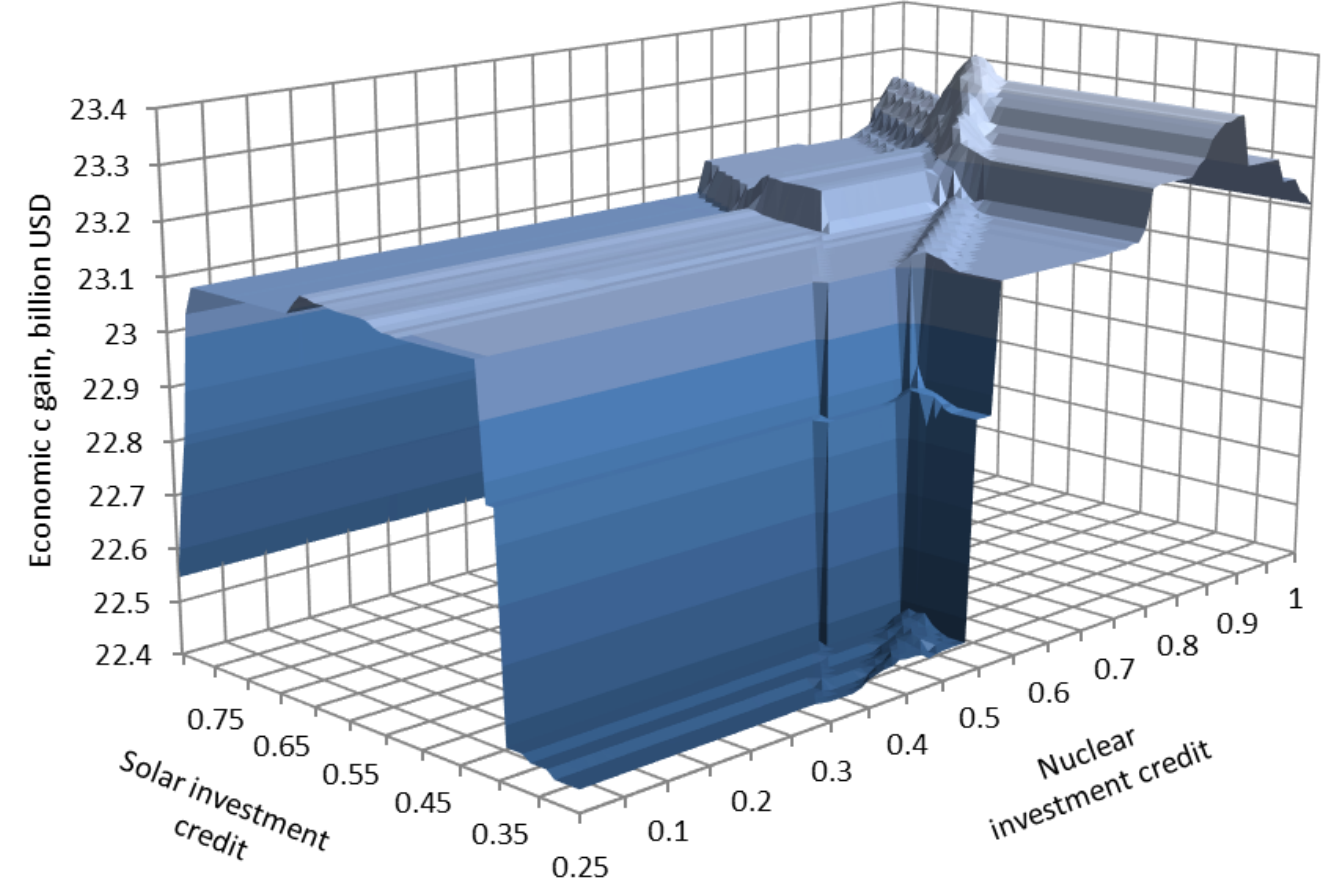

Figure 5.4: Enlarged portion of the grid, Investment-credit scenario 1. 


\section{Validating existing allocations}

As a check on the consistency between current allocations and administered prices, we ran the model under the Current-policy baseline without enforcing any allocation rules. We found that the current allocations are quite close to optimal for the current system of pricing. This should not be surprising, as the basis for granting allocations of natural gas has been to favor those projects likely to add the most value to the Saudi economy. However, larger economic gains can be achieved from increasing the price of natural gas, but these would need to be accompanied by changes in allocations and associated investment credits; in other words, through a holistic optimization of the entire system.

steep drop off in economic gain. This is especially clear with solar because of the decreasing marginal value of a non-dispatchable technology as capacity is increased.

We mentioned in Section 4 that there is a great deal of latitude in defining an investment-credit policy. The investment credit determined by the model at any selected levels of oil and gas prices in this scenario provides the maximum net economic gain. However, as the shape of the solution surface in this figure leads to a near-optimal net economic gain under a wide variety of combinations of the investment credit allocation between solar and nuclear, it provides the aforementioned latitude to allocating this investment credit between the two technologies in a way that is most pragmatic, in order to maximize equilibrium effects such as indirect and induced employment, local supply chain development, and other overall economic benefits that are desirable by the regulator.

\section{Fuel and technology mix}

In all scenarios, all of the available gas is used, as Figure 5.5 shows. Fuel use shifts among the sectors in the different scenarios; for example, the quantity of gas going to the power sector is larger in all alternative scenarios versus the Current-policy baseline, as the gas quotas are not imposed. In the petrochemical sector we constrained exports of high- value products to their current level. The reduction in natural gas use in petrochemicals comes from ending the production of low-value products. If an increase in exports of higher-value products beyond current levels were permitted, more of these products would be produced and exported than in the Current-policy baseline, where the gas quotas are binding. The alternative scenarios have, therefore, the potential for a greater net economic gain than we show here.

Figure 5.6 breaks down electricity production by technology. With the Current-policy baseline the existing capacity is more fully utilized. In the other scenarios more combined-cycle capacity than under current policy is created through adding steam units to gas turbines, saving on fuel consumption. As the scenarios get closer to fuel price deregulation, the use of steam capacity declines significantly. With fuel price deregulation, both nuclear and solar are added to the mix, and there is more combined cycle capacity than under the current policy, but less than with constrained price adjustment.

The change in plant mix results from fuel deregulation leading to the highest fuel prices among the scenarios. On the other hand, providing investment credits for solar and nuclear plants leads to the addition of solar and nuclear capacity. The very high credit attributed to nuclear in Investmentcredit scenario 1 results in a higher penetration of 


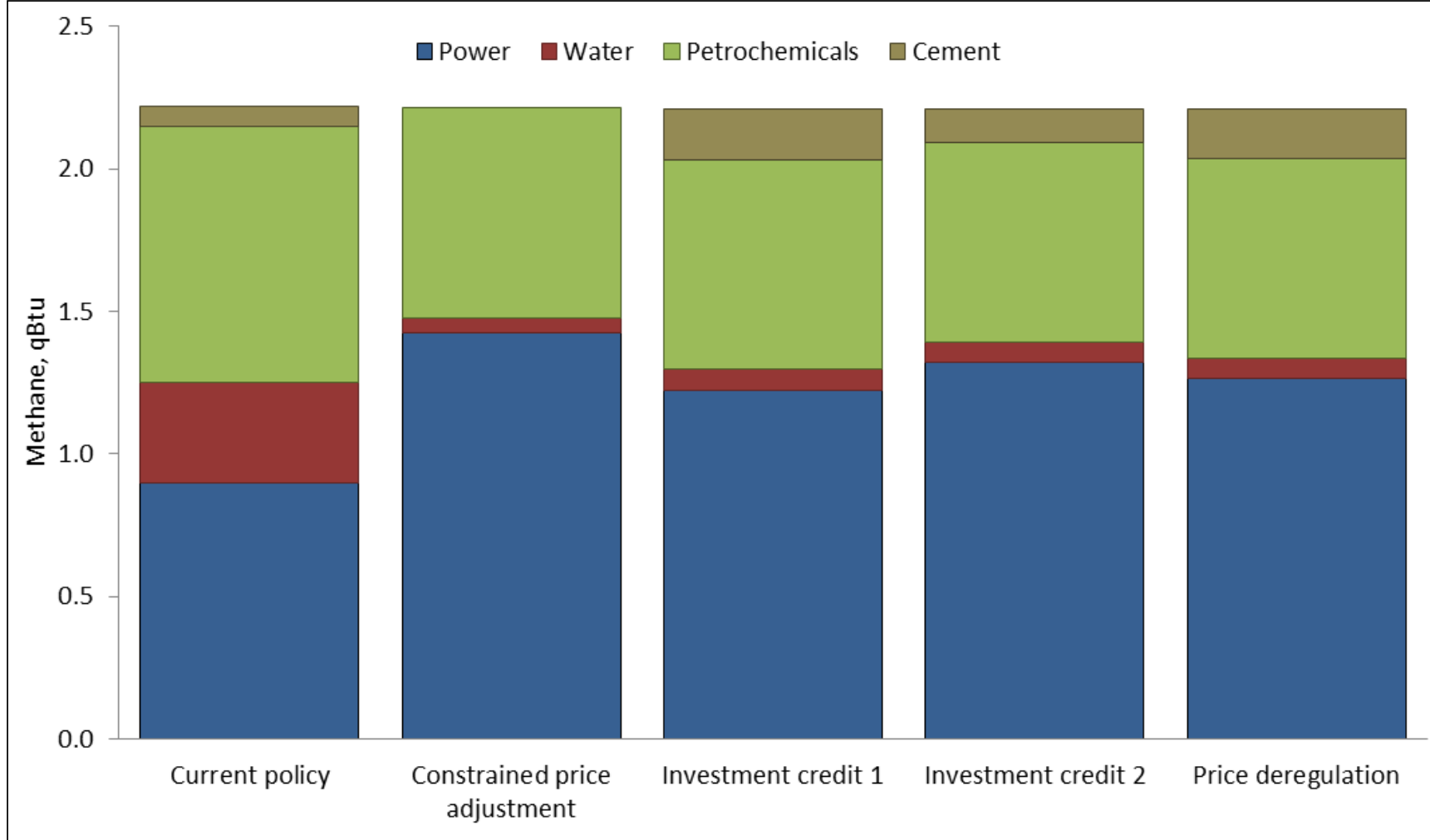

Figure 5.5: Sectoral breakdown of methane consumption, in qBtu.

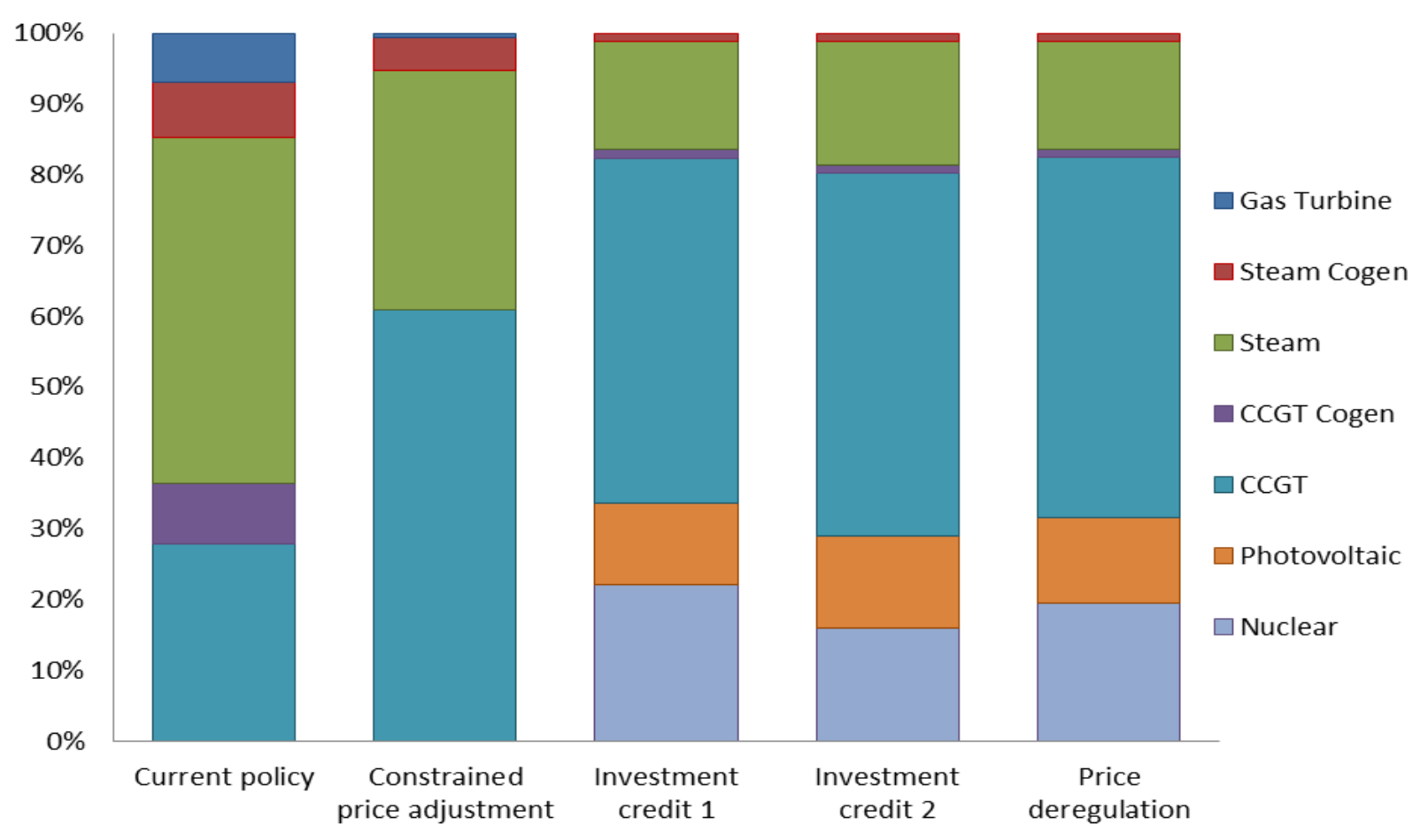

Figure 5.6: Breakdown of electricity production by type of equipment. Note: Gas Turbine: open-cycle (single-cycle) gas turbine; CCGT: combined-cycle gas turbine. 
nuclear. Even with a much lower credit in Investment-credit scenario 2, solar is still economic, despite including the costs of operating extra backup turbines to maintain grid reliability. In both the Investment-credit and Price-deregulation scenarios, crude oil is no longer consumed in the power sector.

\section{Investment needs of the scenarios}

The total upfront investment necessary to achieve the equipment mix in the power sector is 51.4 billion USD for the Price-deregulation scenario, and 53.8 and 47.5 billion USD for Investment-credit scenarios 1 and 2, respectively. Of this upfront investment, the amount of the investment credits in Investmentcredit scenario 1 is 39.1 billion USD (less than two years of the increase in government revenues) and 16 billion USD (less than one year) in Investmentcredit scenario 2 . These investments can, in practice, be phased in optimally and the future multi-period implementation of KEM is intended to provide insights in this regard.

The results illustrate that economic efficiency can be improved in two opposite ways. One direction is to price fuels at their marginal values while providing a subsidy to lower consumer costs. The alternative is that lower prices can still provide the incentive to invest in efficient capital equipment when combined with investment credits for the utilities. This is equivalent in optimization terms to scaling more and more coefficients in the objective function. Once all objective coefficients are scaled proportionately, the optimal solution is the same as in the Pricederegulation scenario.

\section{Sensitivity of the results to the value attributed to the oil saved}

Since Saudi Arabia is a major oil exporting country with spare production capacity, it may value a barrel of oil saved from domestic consumption at a price that is lower than the international market price. For instance, Lahn et al. (2013) reports that Saudi Arabia's Electricity \& Cogeneration Regulatory Authority (ECRA) requires all utilities bidding for power contracts to base their business plans on an oil price of 25 USD per barrel. Discussing the value of a barrel of oil saved in a long-term static framework is outside of the scope of this paper and deserves further study. However, we examine how the capacity mix would adjust and how the economic benefits would change in response to different values of the oil saved in the various scenarios. We first start with the Price-deregulation scenario.

The results are sensitive to how the valuation of the oil saved is defined. We present two alternative definitions: the first lowers the market price of crude oil, the second lowers the market prices of both crude oil and gas condensates (since gas condensates are a partial substitute of oil). In the Pricederegulation scenario studied here, both cases would lead to lower prices for domestic refined products.

\section{The effect on the equipment mix}

Figure 6.1 illustrates the capacity built by type of equipment in the power sector when, from Saudi Arabia's perspective, the value of a barrel of Arabian Light crude saved ranges from 25 USD to the 2011 market price, 107.80 USD, while gas condensates remain valued at the world price. For each value of Arabian Light considered, the same discount to the international market price is applied to the other Arabian crude oil grades. We see that at all oil prices gas turbines would be converted to combined cycle power plants. Solar emerges when the oil price reaches around 45 USD per barrel in the absence of investment credits.

Figure 6.2 presents the capacity built by type of equipment when gas condensates are also valued at a discounted market price. The pattern in the 


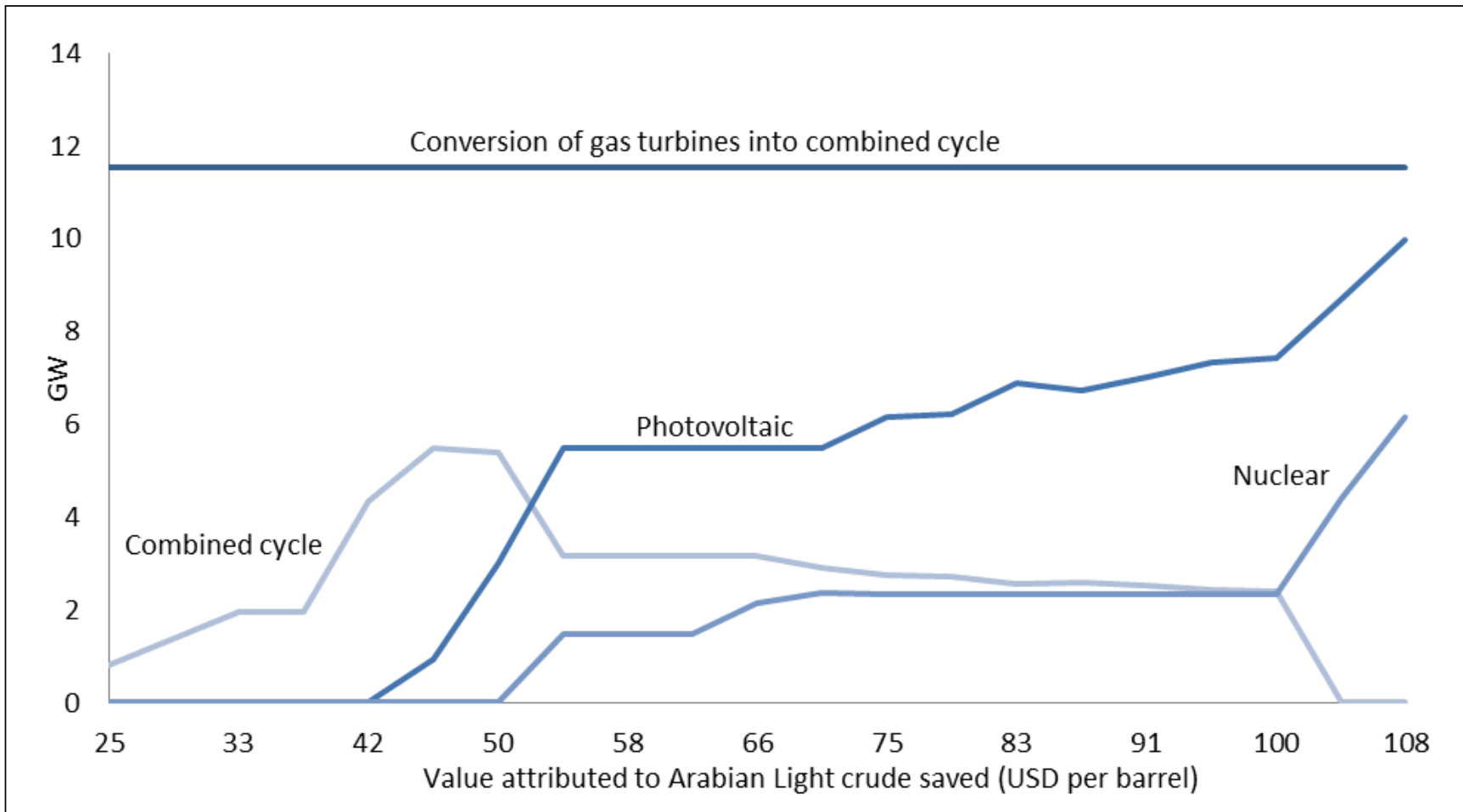

Figure 6.1: Capacity built in the power sector under the Price-deregulation scenario, without the gas condensate price discount.

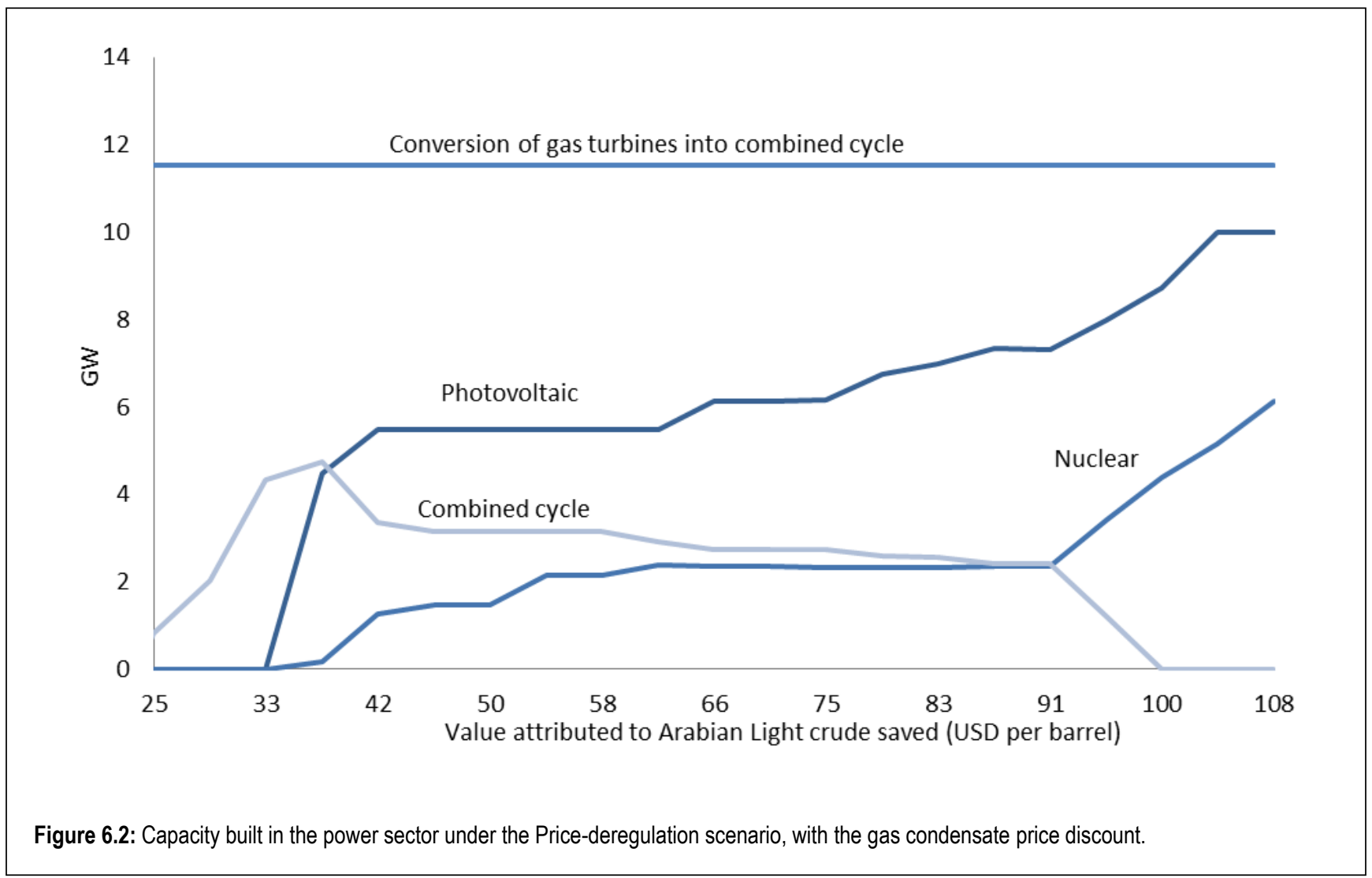




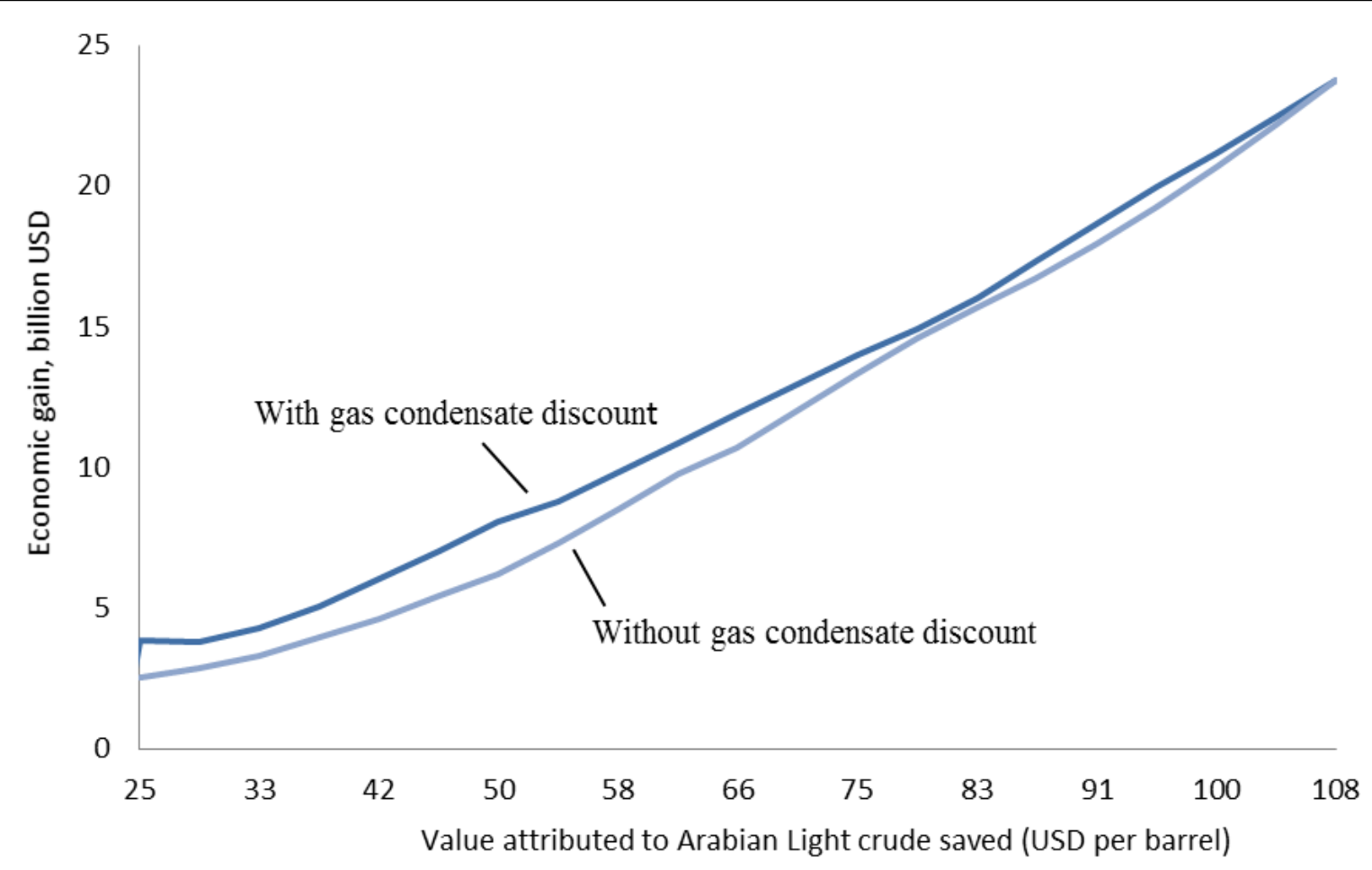

Figure 6.3 - Net annual economic gain under Price-deregulation scenario, with and without gas condensate price discount.

equipment mix at higher oil prices is basically the same as the mix with condensates priced at the world price. The important difference is that solar and nuclear emerge at lower oil prices. The explanation for their emergence at a lower price is that the transfer prices of heavy fuel oil and diesel are higher in the cases with the discounted gas condensate price due to a shift in the mix of inputs and outputs in refineries. Figures 6.1 and 6.2 illustrate the effect of using a price system that differs from market prices and the complexity of defining where these prices apply.

Note that the load factor of photovoltaic power generation is approximately $25 \%$ of that of nuclear, as the former is intermittent by nature while the latter runs as base load. Therefore, the capacity of solar required to meet its share of power production is significantly higher than that of nuclear. This is illustrated by the difference in the proportions of electric power produced in Figure 5.6. compared to the capacities depicted in Figures 6.1 and 6.2.

\section{The economic gain}

As Figure 6.3 shows, under both assumptions of gas condensate pricing the net annual economic gain is roughly the same and grows more or less linearly with the value attributed to the oil saved. At lower values for oil saved, pricing gas condensates the same as crude oil leads to somewhat higher economic gains.

We now examine how the capacity mix adjusts and the economic gain changes when the Investmentcredit scenario is implemented. To simplify the presentation of the results, we consider just the case where gas condensates remain valued at the international market price because these quantities remain outside the OPEC quota. For each value attributed to the oil saved, we keep the administered 


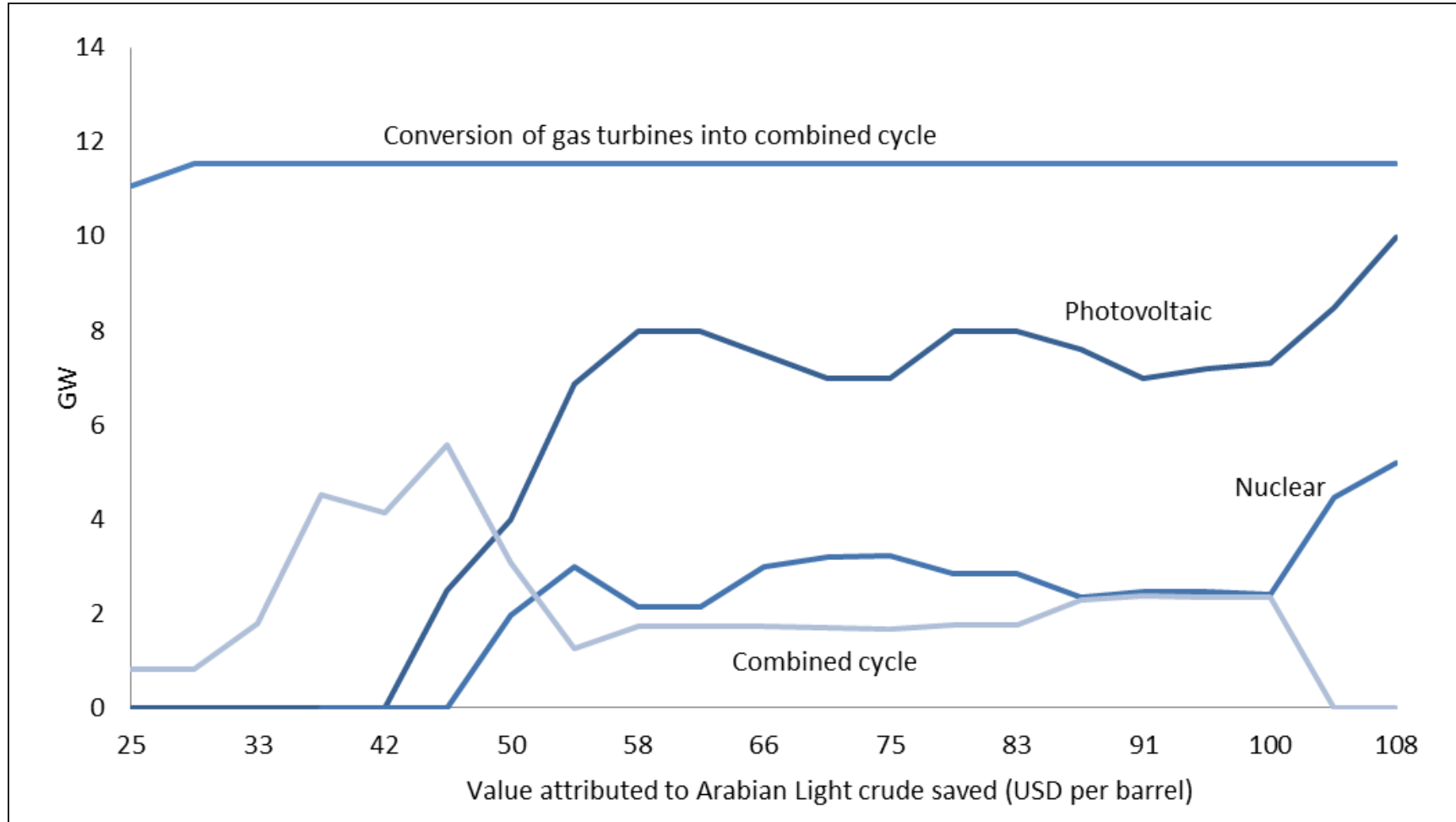

Figure 6.4: Capacity built in the power sector under Investment-credit scenario without gas-condensate price discount.

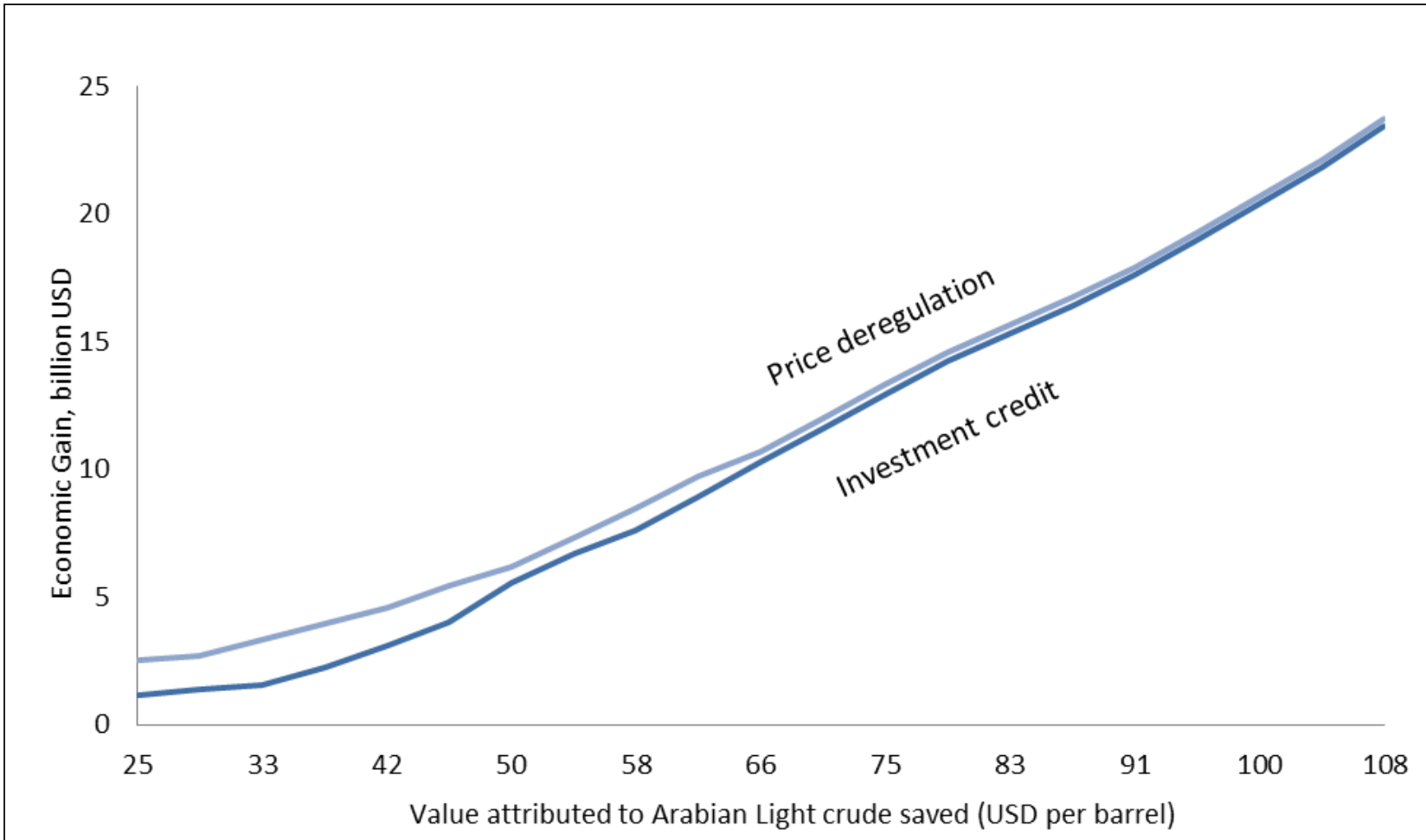

Figure 6.5: Net annual economic gain for the Price-deregulation and Investment-credit scenarios, without gas-condensate price discount. 
price of natural gas at the same level of 1.75 USD per mmBtu and scale the administered price of crude oil by the ratio of the assumed value of oil to the market value of 107.80 USD. We introduce an investment credit for each unit of energy-efficient equipment built in the corresponding Pricederegulation scenario (i.e., solar and nuclear when the value is 107.80 USD per barrel). Thus, we reproduce the original Investment-credit scenario 2 when the assumed value of oil is 107.80 USD per barrel. Figure 6.4 shows the power-generation capacity that is built when we move through the range of values attributed to the oil saved. As shown by Figure 6.5, the economic gains from the Pricederegulation and Investment-credit scenarios remain positive and close even when the crude oil saved is valued at a lower price.

The changes in equipment mix illustrate that the choice of prices has consequences for domestic consumption because organizations make their investment decisions based on the economics of alternatives, given those prices. The internal valuation of the oil saved deserves further investigation to take into account how this price changes choices. Both the effects of alternative prices on equipment choices and the effects of changing how components are valued indicate that using multiple prices for the same product requires a careful policy definition, recognizing that the different pricing policies can have important and sometimes unintended consequences.

\section{Next steps}

The results we present in this paper are based on calibrating our model to the actual numbers for the year 2011. We ask what would have happened in 2011 if the existing capacity could have been supplemented with new plants that would make economic sense if pricing and investment decisions had been done differently. The scale of the potential annual gains is up to $5 \%$ of GDP.

We created this long-term static analysis of the Saudi energy economy in 2011 to demonstrate the scale of the potential savings in domestic oil consumption and the resulting economic gain. Given the potential to save 860,000 bopd and realize a gain of more than $\$ 20$ billion in that year, we will now embark on creating a multi-period version of the model to assist policy makers in deciding what new capacity and displacement of existing capacity will lead to the largest societal benefits in the coming years. We would expect the results to exceed the potential benefits revealed by our initial long-term static model.

A successful implementation of the illustrative policies presented involves going beyond the analysis discussed here and developing a transition plan. Such a plan would balance economic gains and losses through a path of price changes and evolving investment credits and subsidies.

Given that we are working with an aggregate model, the actual gains would likely be different from our estimates. These estimates can be refined by using more detailed planning and operational models before making any investment decisions. The plant types that the model chooses for replacing existing capacity are good choices to meet demand growth and the initial investments in these plants will likely have a large economic impact.

The economic gains with no added costs to consumers come about because we look at energy consumption in Saudi Arabia from a systems perspective, examining how prices set in one part of the energy economy affect decisions in all other parts. Our results cannot be considered a centralplanning process. Rather, the results highlight the 
value of decentralizing decisions through the price mechanism.

Further systems gains could be achieved by considering other policies. For example, coordinating the currently installed capacity for cogeneration of electricity in water production with peak electricity demand through peak-load pricing can lead to reduced energy consumption and economic efficiencies. Another coordination issue that requires a systems perspective is the investment in new refining units in order to reduce the yield of heavy products while crude oil is burned in power plants instead of heavy fuel oil. To improve economic outcomes, a systems perspective again applies when looking at desulfurizing either heavy fuel in oil refineries or flue-gases in power plants. KAPSARC will be examining these issues in the future. 


\section{Appendix 1: Notes on scenario-specific modeling issues}

This appendix contains notes on the model and issues specific to each of the scenarios discussed in this paper.

\section{Current-policy baseline}

For each sector in each region, a constraint limiting the availability of natural gas and its associated dual variable are introduced. Through this set of constraints, the sectors endogenize the quotas in their decision making. The dual variable associated with an availability constraint indicates by how much the sector's total cost/profit would decrease/ increase if the quota for natural gas allocated to the sector were increased by one mmBtu. The sum of the administered price and this dual value represents the marginal value of gas for the sector.

\section{Price-deregulation scenario}

In each region, the price of natural gas becomes the dual variable associated with the supply limit in the upstream oil and gas sub-model.

\section{Constrained-price-adjustment scenario}

Since we are adding a budget constraint to the existing model, we have to satisfy the complementarity conditions of an equilibrium. We do this by adding another non-negative variable that sets every fuel price below marginal value. We price ethane at the marginal value because it is a feedstock and not a fuel. In the model, each inter-sector fuel price is set equal to the corresponding marginal value multiplied by one minus this complementary variable. This complementary variable thus represents a discount from market prices, in order to allow the utility sector to balance its budget. If the budget constraint is not binding, then this variable has the value zero. The flows of gas are endogenously determined.

\section{Investment-credit scenarios}

In mathematical terms, each of these scenarios can be viewed as a solution to a Non-Linear Program subject to Equilibrium Constraints (NLPEC) that maximizes the net economic gain for the given fuel prices. To limit losses in the power and water sectors, the budget constraint used in the Constrained-price-adjustment scenario is introduced into the model. This budget constraint has a complementary variable that is a general credit on investment applied to solar and nuclear power plants. In addition to the general credit, each of these two technologies receives a specific investment credit. Any investment in these technologies thus receives a total credit consisting of the specific credit plus the general credit complementary to the budget constraint. In the model, the power sector acquires capacities at a cost equal to the actual investment cost times one minus this credit.

For any given combination of administered natural gas and crude oil prices, the economic gain is maximized by determining all the equilibria over a grid of specific investment credits. For every investment credit we use a credit increment of one percentage point. All oil-based feedstock prices are fixed to the values used in the current-policy scenario. The administered prices of heavy fuel oil and diesel are set equal to the administered crude oil price times the ratio of the international prices of these fuels to the international price of crude oil. The administered price of ethane remains equal to that of methane, measured in heat value.

The simulations are run by letting gas flow to where it is the most valuable without enforcing sectoral quotas, ensuring the same implicit price in all sectors. Thus, the administered price of natural gas appears only in the budget constraint for the utility sector. The resulting optimal allocation depends on 
the administered price of crude oil. In fact, the current allocation used in the Current-policy scenario is very close to the optimal allocation at the current administered price for crude oil. When gas quotas have to be associated with the system of administered prices (i.e., for low administered prices of natural gas), the resulting consumption levels within sectors give the optimal quotas.

\section{Summary description of the model}

A detailed description of the process by which we built the KAPSARC Energy Model (KEM) is provided in Matar et al. (2013). KEM is a partialequilibrium model formulated as a mixedcomplementary problem that integrates six sectors, each one described in a sub-model. The model can be run as a single-period, static equilibrium model or with multiple time periods with varying planning horizons. Here we operate the model as a singleperiod model that can be rolled forward because of the over-optimization that results from a multiperiod solution. For each year this version of the model has 17,108 variables. The equilibrium is found using GAMS and the PATH solver.

Each sector is assumed to be a price taker, even though most sectors are dominated by large players. This is because domestic prices are either administered or closely monitored and the model takes world prices as given. Figure A1.1 shows the sectors and the flows among them. Every sub-model can also be run separately, taking exogenous prices for inputs used in the sector and exogenous quantities for outputs demanded by other sectors. The power and water sectors, which meet just the local demand, are modeled as cost-minimizers. The refining, cement and petrochemical sectors, which also export and import, are modeled as profitmaximizers. The oil and gas production of Saudi Arabia is taken exogenously from published Saudi Aramco production data. The oil and gas upstream sector is, therefore, represented with available supplies at administered prices and a pipeline structure that minimizes the cost of meeting regional demands for gas and crude oil.

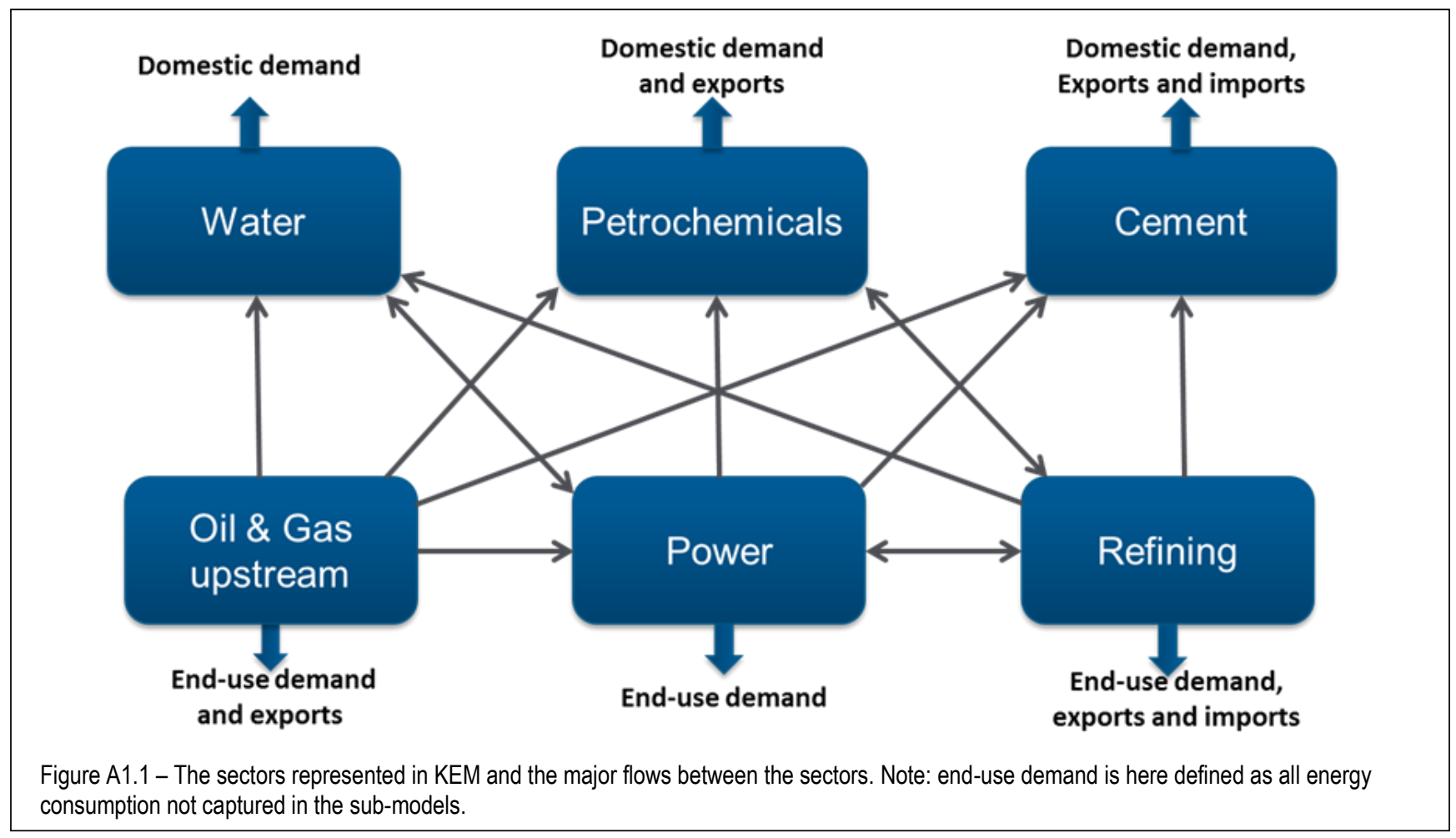


The model splits Saudi Arabia into four regions (Central, East, South, and West) that replicate the Saudi Electricity Company (SEC) operating areas. In every sub-model, the inter-regional movement of inputs and outputs is explicitly modeled, allowing for representing the building of new transportation/ transmission capacities. In every sector outside of the oil and gas upstream sector, investment and production decisions are modeled. For every available technology and their vintages, the model considers the aggregate capacity by region.

The refining sub-model, which aggregates capacity into one refinery per region, is a simplified version of a typical refinery model. The prices of crude oils observed by the refining sector are set at the marginal value in the upstream sector, as Saudi Aramco is the owner of or a major stakeholder in all domestic refineries. The model contains activities for building each type of unit and the ability to operate the units at different severities. Six primary inputs are represented: Arabian Super Light, Arabian Extra Light, Arabian Light, Arabian Medium, Arabian Heavy, and gas condensates. The outputs include nine petroleum products: two grades of gasoline, diesel, liquefied petroleum gas (LPG), jet fuel, heavy fuel oil (HFO), naphtha, petroleum coke, and asphalt. The properties of blended products are specified according to Saudi Aramco requirements. Additionally, the model allows for flexibility in the use of electricity during operation, as power can either be generated on-site or bought from the grid.

The critical feature in modeling electricity generation is that electricity cannot be stored readily. We use what is called a load duration curve to represent the different demand levels that must be met. This curve is a plot of the number of hours in which demand is at or above a given level. It describes the number of hours during which a given quantity of electricity must be produced. The optimal capacity mix contains a range of equipment from low capital cost and high operating cost plants that cover the few peak hours of the year to plants with high capital but low operating costs that cover the base-load demand levels.

For each region, we have estimated the power produced by successive increments of photovoltaic capacity. Based on solar altitude, we first estimated the direct normal irradiation with the ASHRAE Clear Sky Model. The solar output is proportional to the direct normal irradiation. Increments of solar capacity generate solar power that is subtracted from the original load curve. A new load duration curve is then constructed from the load curve, net the solar generation. The size of the spinning reserve is affected by the amount of solar capacity.

The water sub-model optimizes investment and production decisions for desalinated water, with the production of ground water determined exogenously. All major single-purpose and cogeneration technologies used for desalination in Saudi Arabia are included. Cogeneration plants include multipleeffect distillation or multiple-stage flash desalination plants coupled to steam, gas turbine or combinedcycle power plants.

The desalination cogeneration plants currently operate in base load. Because they are operating at full capacity to produce water, they do not vary the mix between electricity and water. However, with sufficient capacity and price incentives they could alter the mix. These plants are represented with variables for capacity, capacity expansion, and a set of operating modes for the mix of electricity and water for each step in the load duration curve.

The Saudi petrochemical industry is export-oriented. The petrochemical sub-model accounts for 22 products spanning basic and intermediate chemicals, polymers, fertilizers, and specialty chemicals. The selection of these products in the model is based on annual reports of the Saudi Basic Industries 
Corporation (SABIC), which owns or is part owner of a majority of the petrochemical facilities in Saudi Arabia. The petrochemical sub-model is linked to refining through the sale of MTBE as a gasoline additive and the purchase of oil-based feedstocks.

The cement sub-model, which allows for the export of finished products and the import of intermediate materials, accounts for the production of three types of cement. We consider the operation of long dry kilns, kilns with preheating, and kilns with both preheating and precalcination. As in the refining sub -model, cement companies are also able to produce electricity on-site or purchase it from the grid.

\section{Calibration of the model}

For the power sub-model, the regional plant capacities are aggregated by technology from the National Electricity Registry of the Electricity and Cogeneration Regulatory Authority (ECRA). The thermal efficiencies of existing plants are calculated based on the actual performance of SEC plants in 2011. Inter-regional transmission capacities, capital and operating costs of thermal plants and transmission equipment, and estimates for the heat rate of new CCGT are from ECRA. The costs

\begin{tabular}{|l|l|}
\hline New combined cycle units & 6,000 Btu per kWh \\
\hline $\begin{array}{l}\text { Gas turbines converted* } \\
\text { into combined-cycle units }\end{array}$ & 6,200 Btu per kWh \\
\hline $\begin{array}{l}\text { Existing combined-cycle } \\
\text { units }\end{array}$ & 8871 Btu per kWh \\
\hline $\begin{array}{l}\text { *We assume that only } 40 \% \text { of the existing gas } \\
\text { turbine capacity can be converted into combined } \\
\text { cycle units and that conversion increases capacity } \\
\text { by 50\%. }\end{array}$ \\
\hline $\begin{array}{l}\text { Table A1.1: Heat rates of combined cycle power plants when methane } \\
\text { is used. }\end{array}$ \\
\hline
\end{tabular}

pertaining to crystalline silicon photovoltaic technology are based on IEA (2010), Fraunhofer ISE (2012) and ESIA/PWC (2012). Tables A1.1 and A1.2 detail parameters used for the operation of combined cycle plants and the costs associated with technologies in the power sector. The regional load duration curves have been derived from the 2011 regional hourly load curves provided by ECRA. Each load duration curve has been discretized into six demand segments. The number of hours included in these segments is 117 (peak), 1280, 1814, 1311, 3232 and 1006 (base).

In the water sub-model, SWCC's existing plants are assumed to operate at the Power-to-Water Ratios (PWR) and thermal efficiencies derived from production quantities and fuel consumption in the SWCC (2011) report. Benchmark PWR from Awerbuch (2006) and Al-Mutaz and Al-Namlah (2004) are used for new plants operated by Independent Water and Power Producers (IWPP). IWPP water production fuel rates were calibrated to match those of SWCC, to avoid under consumption of fuel. Electricity requirements of Multiple Effect Desalination (MED), Multi Stage Flash (MSF) and Reverse Osmosis (RO) are based on values reported in Gude et al. (2010). Capital costs of reverse osmosis and thermal desalination plants have been sourced from investment reports by ACWA power (2013). Non fuel operation costs have been selected using the lower ranges reported by Thye (2010). A wide range of values were available. We selected values that most closely matched the reported total cost of water production by ECRA (2012).

For the petrochemical sub-model, capital and operation costs are adapted from Alfares and AlAmer (2002). Process yields are obtained from Aitani (2006) or estimated from stoichiometric calculations of chemical reaction paths. The values reported by the International Energy Agency (2009) and SICO (2013) are used to estimate the fuel and electricity consumption required for production. 
National production capacity and domestic demand figures are acquired from the Gulf Petrochemicals and Chemicals Association Database (GPC, 2013), and export price and data for 2011 have been calculated from the Central Department of Statistics and Information's (CDSI) export statistics. A constraint in the model limits the quantities exported to those observed in 2011.

Capital investment and operating costs in the refining sub-model are estimated from Hydrocarbon Processing (2004). Unit capacity figures for Saudi refineries are obtained from the IHS Midstream database, and process yields are based on Cerić (2001), Favennec (2001), Hollander et al. (2001), and Gary and Handwerk (2005). The property constraints of blended products are specified based on Saudi Aramco's product specifications. Export and import statistics used for calibration are acquired from the CDSI. Regional power generation capacity within refineries is calculated using published data from the ECRA National Registry and Saudi Aramco, and process electricity consumption values are estimated from Gary and Handwerk (2005) and Hydrocarbon Processing (2004). The data for the domestic demand of refined products in 2011 are obtained from IEA (2013).
The 2011 regional demands for cement are derived from Al-Rajhi Capital (2012), and the market share of each cement type is obtained from Al-Nagadi (2007). Existing production capacities and rawmaterial costs are derived from Al-Jazirah Capital (2011) and correspondence with local companies. The values for energy input required in the different kiln technologies per unit of clinker output are obtained from Princiotta (2011). Published data from Saudi Aramco was the source for the amounts of fuel allocated to cement companies. Mixture specifications, the chemical compositions of the clinker required for the types of cement, and the rate of CKD emission are calculated from van Oss (2005).

Capital investment costs are based on the work of Alsop et al. (2001), Worrell et al. (2008), and the Environmental Protection Agency (2010). The onsite electricity generation capacity data is acquired from ECRA (2012). The values of specific electricity consumption during each process are estimated by Alsop et al. (2001). Quantities and prices of imports and exports in 2011 are gathered from the CDSI. A constraint in the model limits the quantities exported to those observed in 2011.

\begin{tabular}{|l|l|l|l|l|}
\hline Technology & $\begin{array}{l}\text { Capital cost } \\
\text { (USD/kW) }\end{array}$ & $\begin{array}{l}\text { Fixed O\&M cost } \\
\text { (USD/kW-year) }\end{array}$ & $\begin{array}{l}\text { Non-fuel variable } \\
\text { O\&M cost (USD/ } \\
\text { mWh) }\end{array}$ & $\begin{array}{l}\text { Lifetime } \\
\text { (years) }\end{array}$ \\
\hline Steam & 2,120 & 11.2 & 1.64 & 30 \\
\hline Gas turbine & 1,500 & 11.2 & 4.00 & 35 \\
\hline Combined cycle & 1,740 & 12.4 & 3.30 & 35 \\
\hline $\begin{array}{l}\text { Converting gas turbines } \\
\text { into combined cycle }\end{array}$ & 240 & 28 & 3.30 & 25 \\
\hline Photovoltaic & 2,100 & 30 & 0 & 25 \\
\hline Nuclear & 4,500 & 100 & 2.14 & 35 \\
\hline \multicolumn{2}{|l}{ Note: the real discount rate used in the model for the power sector is 6\%. } \\
\hline \multicolumn{2}{|l}{ Table A1.2: Capital and non-fuel operations costs for new equipment in the power sector } \\
\hline
\end{tabular}




\section{References}

ACWA Power, 2013. Our Investments, http:// www.acwapower.com/our-investments.html. Last accessed on July 31, 2013.

Aitani, A., 2006. Propylene Production. Encyclopedia of Chemical Processing, pp. 2461-2466.

Al-Mutaz, I.S., Al-Namlah, A.M., 2004. Characteristic of dual purpose MSF desalination plants. Desalination 166, pp. 287-294.

Al-Nagadi, M., 2007. Concrete Construction Industry - Cement Based Materials and Civil Infrastructure (CBM \& CI). CMB-CI International Workshop, pp. 107.

Al-Rajhi Capital, 2012. Saudi Cement Sector: Cement - Industrial, pp. 10.

Alfares, H., Al-Amer, A., 2007. An Optimization Model for Guiding the Petrochemical Industry Development in Saudi Arabia. Engineering Optimization 34, pp. 671-687.

Aljazirah Capital, 2011. Saudi Cement Sector. Research Department: Sector Reports, pp. 2-13.

Alsop, P., Chen, H., Chin-Fatt, A., Jackura, A., McCabe, M., Tseng, H., 2001. The Cement Operations Handbook: The concise guide to cement manufacture. Tradeship Publications Ltd., Third Edition, pp. 204-217.

Awerbuch, L., 2006. Desalination the sustainable solution and hope for the future generation. The 4th World Water Forum. Mexico.

British Petroleum (BP), 2013. Statistical Review of World Energy 2013, available at http://www.bp.com/ en/global/corporate/about-bp/statistical-review-ofworld-energy-2013.html. Last accessed July 2, 2013. CDSI, 2014. National Accounts Indicators 2013. Ministry of Economy and Planning, pp. 7.
Cerić E., 2001. Crude Oil Assay. INA-Industrija nafte, pp. 10-13.

Council of Ministers resolution No. 55, dated April $11^{\text {th }}, 2006$

Electricity \& Cogeneration Regulatory Authority (ECRA), 2012. Activities \& Achievements of the Authority in 2011, pp. 66-98.

Electricity \& Cogeneration Regulatory Authority (ECRA), 2011. Electricity Tariff, pp. 2.

Emirates Solar Industry Association (ESIA) - PWC, 2012. Sunrise in the desert - Solar becomes commercially viable in MENA.

Environmental Protection Agency, 2010. Available and Emerging Technologies for Reducing Greenhouse Gas Emissions from the Portland Cement Industry, pp. 22.

Fraunhofer, ISE, 2012. Levelized Cost of Electricity: Renewable Energies. Edition: May 30, 2012, pp. 23. Favennec J.P., 2001. Petroleum Refining: Refinery operation and management. Editions Technip, 220-278.

Gary J., Handwerk, G., 2005. Petroleum Refining: Technology and Economics. Marcel Dekker, Inc., Fourth Edition.

Gude V.G., Nirmalakhandan N., Deng S., 2010. Renewable and sustainable approaches of water supply in GCC countries. Renewable and Sustainable Energy Reviews 14, pp. 2641-2654.

Gulf Petrochemicals \& Chemicals Association (GPCA), 2012. GCC Petrochemicals \& Chemicals Industry: Facts \& Figures 2011, pp. 7.

Gulf Petrochemicals and Chemicals Association (GPCA), 2013. Gulf Petrochemicals and Chemicals Database, last accessed June 1, 2013. 
Gulf Petrochemicals and Chemicals Association (GPCA), 2013. Gulf Petrochemicals and Chemicals Database, last accessed June 1, 2013.

Hollander F., Keukens, A., van Es, M., Douwes, B., 2001. Opportunities for optimization of refineries using Thermal Conversion technologies. ABB Lummus Global, pp. 5.

Hydrocarbon Processing, 2004. Refining Processes 2004.

IHS Midstream Database, 2013. https:// edin.ihsenergy.com, last accessed June 29th, 2013. International Energy Agency (IEA), 2013. Energy Statistics of Non-OECD Countries (2013 edition). OECD/IEA, II.356-II.358.

IEA, 2010. Technology Roadmap: Solar photovoltaic energy. OECD/IEA, 8-9.

IEA, 2009. Chemical and Petrochemical Sector: Potential of best practice technology and other measures for improving energy efficiency.

OECD/IEA, September, pp. 14-16.

Lahn, G., Stevens, P., Preston, F., 2013. Saving oil and gas in the Gulf.

Matar, W., Murphy, F., Pierru, A., Rioux, B., 2013. Modeling the Saudi energy economy and its administered components: The KAPSARC energy model. USAEE Working Paper No. 13-150. Available at: http://papers.ssrn.com abstract_id $=2343342$.

Ministry of petroleum and mineral resources, Kingdom of Saudi Arabia. Gas supplies and pricing regulations. Available at http://www2.mopm.gov.sa. Last accessed on July 1, 2013.
Ministry of Water \& Electricity, Kingdom of Saudi Arabia, 2012. Annual report 2011, pp. 66.

Princiotta., F., 2011. Global Climate Change - The Technology Challenge. Springer, New York, pp. 246.

National Commercial Bank, 2012. The Kingdom's Comparative Advantages Propel its Global Position in Petrochemicals: Saudi Petrochemical Sector Review,pp. 3-4.

Saline Water Conversion Corporation (SWCC), 2011. Water Production and Export, Electrical Energy Generation and Export.

SAMA, 2012. Saudi Arabian Monetary Agency: Forty Eighth Annual Report, pp. 356.

Saudi Electricity Company (SEC), 2012. Annual Report 2011, pp. 88.

SICO Research, 2013. Saudi Petrochemicals: the gas price question, pp. 2-3.

Thye, J.F., 2010. Desalination: can it be greenhouse gas free and cost competitive. Master's Project. Yale

School of Forestry and Environmental Studies. Van Oss, H., 2005. Background Facts and Issues Concerning Cement and Cement Data. United States Geological Survey, Open-File Report 20051152 , pp. 15-33.

Worrell, E., Galitsky, C., Price, L., 2008. Energy Efficiency Improvement Opportunities for the Cement Industry. Lawrence Berkley National Laboratory, pp. 9-10.

WTO, 2005. Report of the Working Party on the Accession of the Kingdom of Saudi Arabia to the World Trade Organization. Available at http:// www.wto.org. 


\section{Acknowledgements}

We gratefully acknowledge the methodological help provided by Yves Smeers, who suggested the complementarity framework with administered prices used here, and Adnan Shihab-Eldin, who provided insightful comments on earlier results. Moreover, The Electricity and Cogeneration Regulatory Authority (ECRA) of Saudi Arabia was very helpful in providing data on and insights into the utilities sectors.

\section{About the authors}

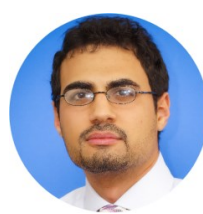

Walid Matar is a Senior Research Analyst developing energy systems models. Prior to joining the Center in August 2011, he obtained a B.Sc. degree in mechanical engineering from the University of South Carolina. He then received a graduate degree in the same field from North Carolina State University. On his return to Saudi Arabia, he worked at King Abdullah University of Science and Technology (KAUST) in the area of business incubation.

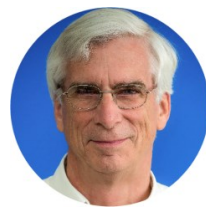

Frederic Murphy is a Senior Visiting Fellow collaborating with the energy systems modeling work at KAPSARC. $\mathrm{He}$ is also Professor Emeritus, Marketing and Supply Chain Management (MSCM) at the Fox School of Business at Temple University.
Prior to Temple University, he worked at the Energy Information Administration (EIA) of the U.S. Department of Energy, forecasting and analyzing policy impacts on energy markets. Prof. Murphy worked on all the energy forecasting models for the EIA, including the National Energy Modeling System (NEMS) model.

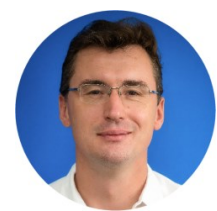

Axel Pierru is a Research Fellow, leading KAPSARC's energy systems modeling work. He joined KAPSARC after 15 years at IFP Energies Nouvelles. He led research, consulting, and training projects and taught graduate courses at IFP School, supervising Ph.D. students. Axel received his Ph.D. in economics from Pantheon-Sorbonne University (Paris) and has published numerous research papers in academic journals, mainly in the fields of energy economics and modeling, corporate finance, and the price of oil.

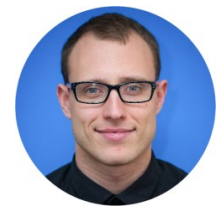

Bertrand Williams-Rioux is a Senior Research Analyst developing energy systems models. He graduated from King Abdullah University of Science and Technology (KAUST) after completing a Master's thesis in Computational Fluid Dynamics. $\mathrm{He}$ also has a Bachelor's degree in Atmospheric Physics and Chemistry from McGill University, in Montreal, Canada in 2008. He previously spent an eight month internship as a research assistant at the Canadian Space Agency. 